\title{
A numerical study on the flow through a plane symmetric sudden expansion with a fence viewed as a diffuser
}

\author{
D. K. Mandal ${ }^{\text {* }}$, S. Bandyopadhyay ${ }^{2}$ and S. Chakrabarti ${ }^{3}$ \\ ${ }^{1,2}$ Dept. of Mechanical Engineering, College of Engg. \& Management, Kolaghat, P.O: K.T.P.P. Township, Midnapore (E) - 721 171, West Bengal, INDIA \\ ${ }^{3}$ Dept. of Mech. Engg., Bengal Engineering and Science University, Shibpur, Howrah - 711 103, West Bengal, INDIA \\ "Corresponding Author: e-mail: dipkuma@yahoo.com
}

\begin{abstract}
The numerical analysis and performance simulation of a sudden expansion with fence viewed as a diffuser are presented in this paper. SIMPLE algorithm is used to solve two-dimensional steady differential equations for conservation of mass and momentum. The Reynolds number is in the range of 20 to 100 and fence subtended angle (FSA) between $10^{\circ}$ to $30^{\circ}$. The location of fence from throat varies from 0.2 to 2.6. An aspect ratio for all computations is taken to be 2 . The effect of each variable on average static pressure, diffuser effectiveness, distance of maximum static pressure rise and average stagnation pressure have been studied in detail, and comparisons are made with respect to simple sudden expansion without fence. It is revealed from the computation for lower Reynolds number regime that the effectiveness with fence offers benefit depending on the positioning of the fence and fence subtended angle. Fence at any location always offers benefit at relatively higher Reynolds number at any value of fence subtended angle. Fence subtended angle and location of fence have no appreciable impact on distance of maximum static pressure rise from throat and average stagnation pressure drop at a particular value of Reynolds number.
\end{abstract}

Keywords: Sudden expansion, fence, Reynolds number, static pressure, diffuser effectiveness, stagnation pressure.

DOI: http://dx.doi.org/10.4314/ijest.v3i8.18

\section{Introduction}

A diffuser is an expanding section of a fluid-carrying duct, where the fluid kinetic energy is converted to static pressure head. The geometry of sudden expansion can be found in use in numerous equipments, such as heat exchangers, combustion chambers, mixing vessels, reactors, biological systems etc. One of the most important applications of a diffuser is to use it ahead of the combustion chamber of an aircraft gas turbine unit. In a gas turbine unit, the diffuser is placed between the compressor and the combustor that has the primary function of reducing air velocity to ensure efficient combustion at a low pressure loss that sustains a stationary flame in the combustor. Massive improvements in recent years, in the technology of different components of aircraft gas turbines has placed a great emphasis upon the requirement and consequently the development of short and effective diffusers which need to be placed between the compressor and combustor. This challenge has led researchers to have an extensive research on the performance of short length, high performance diffusers.

Several experimental and numerical investigations have been performed to increase the understanding of the fluid dynamics phenomena and critical Re in backward-facing step flow. Experimental investigations of plane sudden-expansion flows have been reported by Durst et al. (1974), Cherdron et al. (1978), Sobey and Drazin (1986), Fearn et al. (1990) and Durst et al. (1993), who used laser-Doppler anemometry to measure the velocity distributions, including those in close proximity of the recirculation regions, and flow visualization to show the nature of laminar flows. Their study for channels with moderate expansion ratios have demonstrated that when Re is relatively low the flow in the channel is steady, two-dimensional, and symmetric with two separation zones near the expansion corners, the size of which increases with Re. However, at higher values of Re, the flow stays two- 
dimensional and steady but becomes asymmetric with two separation zones of different lengths which attach on either the upper or the lower wall of the channel. At even higher Re, additional recirculation zones appear along the channel walls.

For two-dimensional numerical simulations, the backward-facing step has been the subject of experimental (Armaly et al. 1983; Kosma 2000; Lee et al. 2000) and numerical investigations (Guerrero and Cotta 1996; Koutmos and Mavridis 1997; Choi et al. 1999). Denham and Patrick (1974) have conducted experiments on laminar flow over a backward facing step with an expansion ratio of 3. Velocity profiles and reattachment lengths of the primary recirculation zone were measured in the steady twodimensional regime for Reynolds numbers up to 344. Ghia et al. (1989) have computed two-dimensional solutions of the backward-facing step flow throughout the laminar regime and found good agreement with the two dimensional flows have been observed by Armaly et al. (1983).

Instabilities of the step flow are investigated numerically by Kaiktsis et al. (1991, 1996) using the same expansion ratio as Armaly et al. (1983). The two-dimensional, absolute, linear stability of this flow has been examined extensively and are discussed in several publications (Gartling 1990; Gresho et al. 1993; Fortin et al. 1997). Their computational studies have established that the two-dimensional laminar flow is linearly stable with respect to two-dimensional perturbations up to a Reynolds number of at least $\mathrm{Re}=600$. Kobayashi et al. (1992) have studied the recirculating flow around a backward-facing step by large eddy simulation (LES). In the recirculating region, three eddy structures are observed in the instantaneous streamline distributions, and the location of the reattachment point varies according to the size of these eddies.

The dynamics of a laminar flow in a symmetric channel with a sudden expansion is studied by Hawa and Rusak (2001). A threedimensional stability analysis without sidewalls at an expansion ratio of 2 has been performed by Barkley et al. (2002). They have reported the three-dimensional computational stability analysis of flow over a backward-facing step with an expansion ratio of 2 at Reynolds numbers between 450 and 1050. Chakrabarti et al. (2003) have made an extensive study on the performance of sudden expansion from the perspective of a diffuser.

The two dimensional simulation studies of Dejoan and Leschziner (2004) in the periodically perturbed flow over a backwardfacing step identify the involvement of both shear layer and shedding-type instabilities in the promotion of reattachment. The numerical solution of incompressible laminar flows has been carried by Manica and Bortoli (2004) through a channel with 1:3 sudden expansion for power-law Fluids. Beaudoin et al. (2004) in their three-dimensional backward-facing step flow study have observed the presence of longitudinal vortices. The critical-Reynolds-number effect on the flow behavior of the three-dimensional backward-facing step flow has been studied by Nie and Armaly (2004). They have concluded that the flows with a Reynolds number Re value of less than 400 are of the laminar flow type, Re falling between 400 and 3400 could, however, yield transitional flows. Meri and Wengle, (2004) have studied turbulent flow by using Direct Numerical Simulation (DNS) and Large-Eddy Simulations (LES) over a backward-facing step with a fully developed channel flow utilized asatime-dependent inflow condition. The two-dimensional laminar flow of an incompressible viscous jet through a channel with a sudden expansion is analyzed by Revueltaa (2005) in the case of a large expansion ratio. The eddy structures and their mutual interactions in a three-dimensional channel with a backward-facing step for the transitional Reynolds number 900 have been investigated numerically by Sheu and Rani (2006). The laminar flow of Newtonian fluids in axisymmetric diffusers has been numerically investigated by Rosa and Pinho (2006) to evaluate the pressure-loss coefficient as a function of Reynolds number, diffusion angle and expansion ratio. The numerical study has been carried out by Neofytou (2006) to show the transition from symmetry to asymmetry with respect to the flow through a symmetric 1:2 sudden expansion. Blackburn et al. (2008) have carried out a detailed investigation of the convective instability and transient growth in flows over a backward-facing step in the Reynolds number range of 0 to 500 . Poole et al. (2007) have studied numerically the effect of flow of three viscoelastic fluids, through a two-dimensional 1:3 planar sudden expansion.

Numerical simulations are performed by Mohanarangama et al. (2008) for dilute gas-particle flows over two-dimensional turbulent backward-facing step geometry to examine the effects of step heights on turbulent separated flow with particles and their inherent dispersion behavior. An experimental investigation of the turbulent flow downstream of a planar sudden expansion has been performed by Casarsaa and Giannattasio (2008) for Reynolds number of 104 and expansion ratio of 3. The axial variations of the pressure and area-averaged void fraction across the sudden expansion are investigated experimentally by Ahmed et al. (2008) to characterize the development of air-oil two-phase flow downstream of sudden expansions with area ratios of 0.0625 and 0.25. The internal flow over a backward-facing step in the transitional regime has been studied by Schafer et al. (2009) based on direct numerical simulations. An extensive exercise has been made by Ghosh et al. (2009) to optimize the diffuser shape. The flow separation phenomenon in an asymmetric plane diffuser with $8.5^{\circ}$ opening angle has been studied experimentally by Tornblom (2009) for Reynolds number of 38000. Senthil Kumar et al. (2010) have studied the combined effect of thermo-solutal buoyancy forces on the recirculatory flow behavior in a horizontal channel with backward-facing step and the ensuing impact on heat and mass transfer phenomena.

Some research activities have also been initiated to study the flow characteristics and performance of sudden expansion configurations with some modifications e.g., incorporation of suction on the wall, incorporation of fence in the diffusion zone, incorporation of blowing on the wall, incorporation of diverging channel after sudden expansion etc. Among them, Heskestad $(1965,1968)$ has performed experimentation employing a suction slot at the convex discontinuity of a step expansion in a circular pipe. He has compared his results with that of a conical diffuser and concluded that better pressure recoveries may be obtained by providing suction than a conical diffuser particularly when the dimensionless length of a diffuser is less than five. The 
characteristics of annular diffusers have been presented by Ainley (1945), Johnston (1953), and Howard et al. (1967). Adkins (1975) have showed by experimental work that an appreciable amount of static pressure recovery can be achieved by incorporating both bleeding and a fence downstream of the vortex region. Raghunathan and Cooper (2000) have conducted experiments in short wide-angle diffusers. The experiments consist of slots normal to the surface and a combination of slots normal and inclined to the surface. Passive control with inclined slots produces modest improvements in pressure recovery and significant increase in the stall angle. Chakrabarti et al. (2002) have made a numerical study of the performance of a diffuser with bleed slot in different locations at vertical and horizontal walls of a plain sudden expansion. They have achieved the best performance when suction slot has been placed at the top corner in the vertical wall. Walker et al. (2004) have made experimental and computational studies of hybrid diffusers for gas turbine installations. The effects of buoyancy assisting force and duct's aspect ratio on flow bifurcation and on heat transfer for three-dimensional laminar mixed convection in a vertical plane through symmetric sudden expansion with expansion ratio of two for Reynolds number of 800 is simulated by Thiruvengadam et al. (2007).

An experimental investigations of separated flows in fully stalled wide-angled diffusers have been carried out by Kibicho and Sayers (2008). The effect of the diffuser angle on the flow and heat transfer is studied by Lan et al. (2009) in a plane asymmetric diffuser with an expansion ratio of 4.7. Chakrabarti et al. (2008) have carried out a performance simulation of a sudden expansion with fence for the Reynolds number in the range of 20 to 100, non dimensional distance of fence from throat for 0 to 2 and fence subtended angle of $10^{\circ}$ for the aspect ratio of 2 . They have obtained the best performance of the diffuser, when the position of the fence has been located from the throat, at a non dimensional distance of around 1 for higher flow Reynolds number in the case of fence subtended angle of $10^{\circ}$. In the previous work of Chakrabarti et al (2010), they have investigated the effect of Reynolds number, fence subtended angle and position of fence on the average static pressure and diffuser effectiveness for a diffuser having configuration of sudden expansion with fence. In their work, they have considered some typical values of distance of fence from throat. They have not studied the physics in detail. They also have not studied variation of average stagnation pressure, and the distance of maximum average static pressure rise from throat.

From the literature review presented above, it is evident that many researchers have conducted numerical and experimental studies on simple sudden expansion as well as simple sudden expansion with some modifications like using only suction, and using both suction and fence on the perspective of diffuser. It is evident that very few numerical works has been carried out on the performance of sudden expansion with fence only from diffuser view point. Therefore, in the present work, an attempt has been made to investigate the effect of important parameters like Reynolds number, fence subtended angle, and location of fence from throat on average static pressure, diffuser effectiveness, distance of maximum static pressure rise from throat and average stagnation pressure for a diffuser having configuration of sudden expansion with fence.

\section{Mathematical formulation}

\subsection{Computational Domain}

A schematic diagram of the computational domain is illustrated in Figure 1.

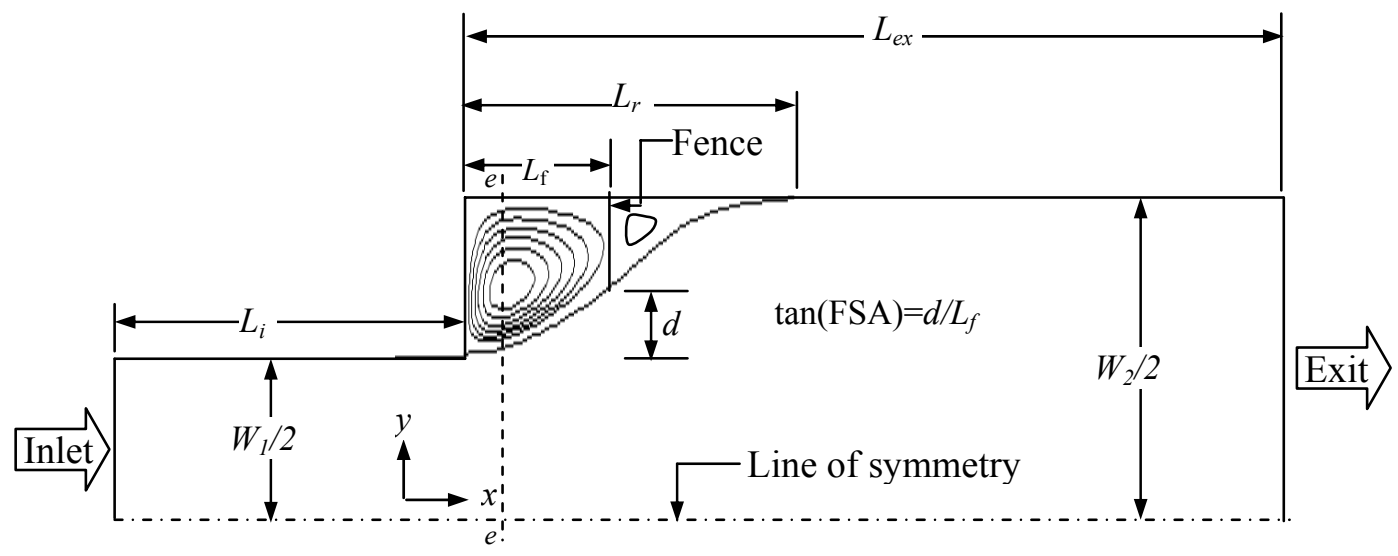

Figure 1. Computational domain.

\subsection{Assumptions}

The flow under consideration has been assumed to be steady, two-dimensional, laminar and axisymmetric, and fluid is considered to be Newtonian and incompressible.

\subsection{Governing Equations}

The following dimensionless variables are defined to obtain the governing conservation equations in the non-dimensional form; 
Lengths: $x^{*}=x / W_{1}, y^{*}=y / W_{1}, L_{i}^{*}=L_{i} / W_{1}, L_{e x}^{*}=L_{e x} / W_{1}, L_{r}^{*}=L_{r} / W_{1}, L_{p}^{*}=L_{p} / W_{1}, L_{f}^{*}=L_{f} / W_{1}$.

Velocities: $u^{*}=u / U, v^{*}=v / U$

Pressure: $p^{*}=(p+\rho g y) / \rho U^{2}$

With the help of these variables, the mass and momentum conservation equations are written as follows,

$$
\begin{aligned}
& \frac{\partial u^{*}}{\partial x^{*}}+\frac{\partial v^{*}}{\partial y^{*}}=0 \\
& u^{*} \frac{d u^{*}}{d x}+v^{*} \frac{d u^{*}}{d y}=-\frac{\partial p^{*}}{\partial x^{*}}+\frac{1}{\operatorname{Re}}\left[\frac{\partial}{\partial x^{*}}\left(\frac{\partial u^{*}}{\partial x^{*}}\right)+\frac{\partial}{\partial y^{*}}\left(\frac{\partial u^{*}}{\partial y^{*}}\right)\right] \\
& u^{*} \frac{d v^{*}}{d x}+v^{*} \frac{d v^{*}}{d y}=-\frac{\partial p^{*}}{\partial y^{*}}+\frac{1}{\operatorname{Re}}\left[\frac{\partial}{\partial x^{*}}\left(\frac{\partial v^{*}}{\partial x^{*}}\right)+\frac{\partial}{\partial y^{*}}\left(\frac{\partial v^{*}}{\partial y^{*}}\right)\right]
\end{aligned}
$$

Where, the flow Reynolds number, $\operatorname{Re}=\frac{\rho U W_{1}}{\mu}$.

\subsection{Boundary Conditions}

Four different types of boundary conditions have been applied to the present problem. They are as follows,

1. At the walls: No slip condition, i.e., $u^{*}=0, v^{*}=0$.

2. At the inlet: Axial velocity has been specified and the transverse velocity has been set to zero, i.e., $u^{*}=$ specified, $v^{*}=0$.

Fully developed flow condition has been specified at the inlet, i.e., $u^{*}=1.5\left[1-\left(2 y^{*}\right)^{2}\right]$.

3. At the exit: Fully developed condition has been assumed and hence gradients have been set to zero, i.e., $\partial u^{*} / \partial x^{*}=0$, $\partial v^{*} / \partial x^{*}=0$.

4. At the line of symmetry: The normal gradient of the axial velocity and the transverse velocity have been set to zero, i.e., $\partial u^{*} / \partial y^{*}=0, v^{*}=0$.

\subsection{Numerical Procedure}

The partial differential equations (1) - (3) are discretised by a control volume based finite difference method. Power law scheme is used to discretise the convective terms, Patankar (1980). The discretised equations are solved iteratively by SIMPLE (SemiImplicit Method for Pressure-Linked Equations) algorithm, using line-by-line ADI method. The convergence of the iterative scheme is achieved when the normalized residuals for mass and momentum equations summed over the entire calculation domain fall below $10^{-8}$.

As stated in the assumptions, since the flow is assumed to be fully developed at the exit, the exit is kept far away from the throat. Accordingly, the non-dimensional exit length of 100 is chosen during the computation. The inlet length is considered to be 1 due to the assumption of fully developed velocity profile at the inlet of the computational domain. Non-uniform and staggered grid arrangements have been selected in both $\mathrm{x}$ and $\mathrm{y}$ directions such that the grid node concentration increases in the regions close to the walls of the duct.

\subsection{Grid-independence Test}

The distributions of grid nodes have been considered non-uniform and staggered in both coordinate direction allowing higher grid node concentrations in the region close to the wall. In this case, grid sensitivity analysis, known as Richardson Extrapolation has been adopted for rectangular computational domain in between inlet and exit section (x directional non dimensional length of 101 and y directional non dimensional length of $1.0 \mathrm{i}, \mathrm{e} W_{2} / 2$ ). The detailed analysis results using the above technique are presented in Table 1. The computations have been carried out for $\mathrm{Re}=100$, considering sudden expansion without fence with aspect ratio of 2. Four different numbers of meshes for both the coordinates, represented by $M_{1}, M_{2}, M_{3}$ and $M_{4}$, arranged according to their increasing degree of fineness, have been used for the study. The corresponding grid levels are marked as 1, 2, 3 and 4 respectively. Thus, grid level 1 represents the coarsest grid, while level 4 represents the finest one. The grid dependent parameters, that have been compared, are the recirculation length $\left(L_{r}^{*}\right)$ (calculated from throat), the maximum wall pressure $\left(P_{W}{ }^{*} \max \right)$, diffuser effectiveness $\left(\eta_{d}\right)$, maximum value of stream function $\left(\Psi_{\max }\right)$, and distance of maximum static pressure from throat $\left(L_{P}{ }^{*}\right)$. These values are shown in the Table 1. The corresponding values of the Richardson's Extrapolated data of the exact solution of the above parameters, as the grid size theoretically approaches zero value, are also computed and listed in the last column of Table 1. Using 
these exact values of the above parameters, the absolute and the relative errors of the numerical solutions on all the four grid levels have been determined.

Table 1. Results of grid independence test

\begin{tabular}{llllll}
\hline $\begin{array}{c}\text { Mesh Size } \\
(\mathrm{x}, \mathrm{y})\end{array}$ & $M_{1}(56 \times 8)$ & $M_{2}(112 \times 16)$ & $M_{3}(224 \times 32)$ & $M_{4}(448 \times 64)$ & $\begin{array}{l}\text { Richardson's } \\
\text { Extrapolation }\end{array}$ \\
\hline$L^{*}{ }_{r}$ & 3.71 & 3.49 & 3.47 & 3.43 & 3.42 \\
Error & 0.29 & 0.07 & 0.05 & 0.0072 & - \\
Error $(\%)$ & 8.47 & 2.04 & 1.46 & 0.39 & - \\
$P_{W}{ }^{*} \max$ & 0.24113 & 0.2790 & 0.300 & 0.3138 & 0.3184 \\
Error & 0.077 & 0.0394 & 0.0184 & 0.0046 & - \\
Error (\%) & 24.27 & 12.37 & 5.77 & 1.44 & - \\
$E f f\left(\eta_{d}\right)$ & 53.54 & 65.42 & 71.21 & 71.15 & 71.13 \\
Error & 17.59 & 5.73 & 0.08 & 0.02 & - \\
Error (\%) & 24.72 & 8.02 & 0.11 & 0.03 & - \\
$\Psi_{\max }$ & 0.5152 & 0.5202 & 0.5219 & 0.5211 & 0.5208 \\
Error & 0.0056 & 0.0006 & 0.0011 & 0.0003 & - \\
Error $(\%)$ & 1.07 & 0.12 & 0.21 & 0.05 & - \\
$L_{P}{ }^{*}$ & 6.75 & 6.80 & 6.70 & 6.43 & 6.34 \\
Error & 0.41 & 0.46 & 0.36 & 0.09 & - \\
Error $(\%)$ & 6.46 & 7.25 & 5.67 & 1.42 & - \\
\hline
\end{tabular}
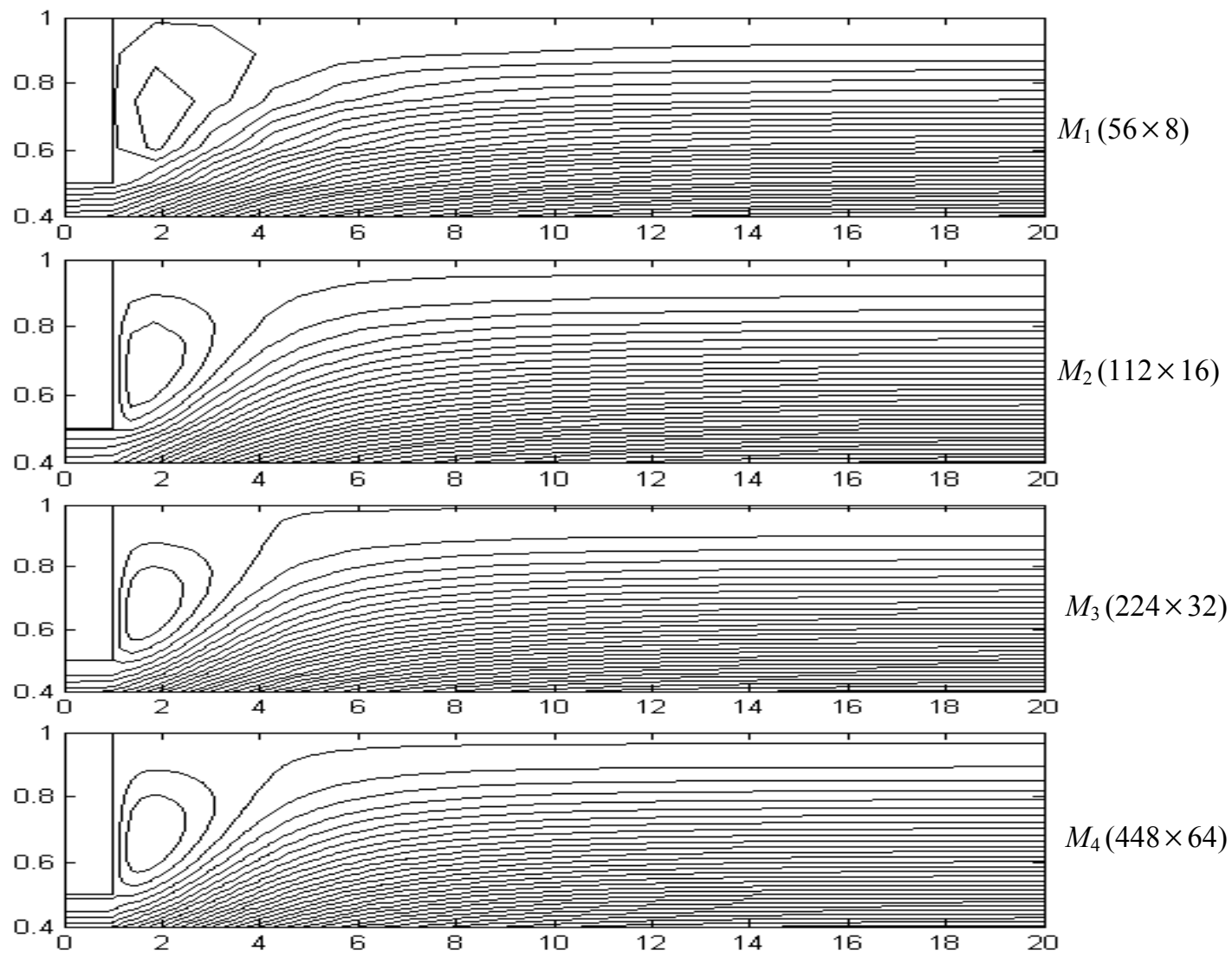

Figure 2. Streamline contours for different grids in grid independence study

It is obvious that the errors monotonically converge towards zero and are $0.39 \%$ only for the recirculation length $\left(L_{r}^{*}\right), 1.44 \%$ for the maximum wall pressure $\left(P_{W \max }{ }^{*}, 0.03 \%\right.$ for diffuser effectiveness $\left(\eta_{d}\right), 0.05 \%$ for stream function $\left(\Psi_{\max }\right)$, and $1.42 \%$ for maximum static pressure from throat $\left(L_{P}{ }^{*}\right)$ respectively when the grid level 4 is adopted. Accordingly the number of meshes (cells) in $x$ and $y$ directions for the earlier mentioned rectangular domain have been considered as $448 \times 64$. During the grid independence study, the number of meshes (cells) in $x$ and $y$ directions for the inlet section of Figure 1 have been held constant at $20 \times 28$ 
typically, i. e., 21 nodes along the $x$ direction and 29 nodes along the $y$ direction. This appears to be reasonable because, it is the after throat section i. e, of prime importance as far as the performance of sudden expansion, viewed as a diffuser, is concerned. In the exit section of Figure 1, the number of meshes (cells) in $x$ and $y$ direction, have been considered to be $428 \times 64$ i. e., 429 nodes in $x$ direction and 65 nodes in $y$ direction. The grid independence study with respect to flow characteristics is substantiated by streamline contour in the Figure 2. The figure shows that the length of recirculation length $\left(L_{r}^{*}\right)$ decreases with the increase in grid size, and finally the magnitude comes near the Richardson's value to some extent with the final grid.

\subsection{Validation of computational results}

In order to validate the accuracy of the numerical model, comparisons are made between the numerical results and the experimental data reported by Durst et al (1974). The experimental geometry used in Durst et al. (1974) is considered in the simulation, which is shown in Figure 3. The computations have been carried out for Reynolds number of 56 for aspect ratio of 3. Axial locations of presented velocity profile in the paper (Durst et al. 1974) have been converted to the locations in accordance with our consideration, and accordingly the results have been placed in Figure 3. It shows the variations of axial velocity profiles at different locations of downstream of the sudden expansion, along with the experimental measurements of Durst et al. (1974). As observed, the numerical results are in good agreement with the experimental data.

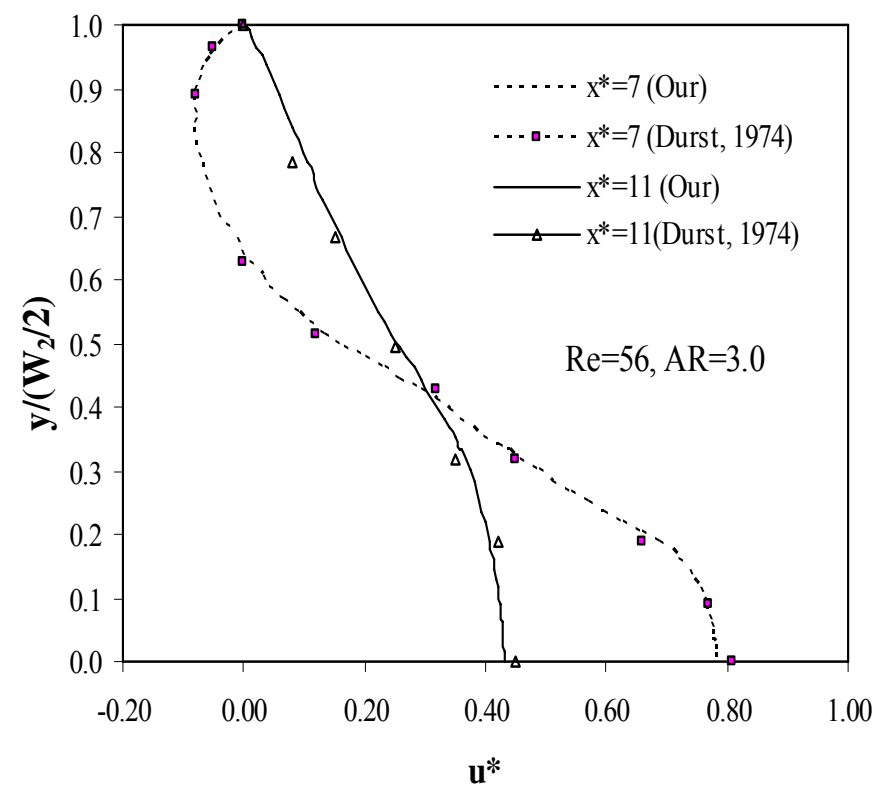

Figure 3. Axial velocity profiles at different axial locations

\section{Results and discussion}

The major results of the present study are presented in this section. The parameters of this study are:

i) Reynolds number, $20 \leq R e \leq 100$

ii) Fence subtended angle, $10^{\circ} \leq F S A \leq 30^{\circ}$

iii) Distance of fence from throat, $0.2 \leq L_{f}^{*} \leq 2.6$

iv) Aspect ratio, $A R=2$

v) Inlet velocity distribution - fully developed

In the figures, any curve represented by $F S A=0$ or $L_{f}{ }^{*}=0$ is considered as the configuration of a simple sudden expansion without any fence.

\subsection{Variation of Average Static Pressure along the Length}

The rise in static pressure is an important parameter in assessing the performance of a diffuser. A properly designed diffuser should ensure a high static pressure rise while having minimum stagnation pressure loss. In the present work, the following mathematical formulation is used to compute the average static pressure. 


$$
\mathrm{p}_{\mathrm{avg}}=\frac{\int \mathrm{pdA}}{\int \mathrm{dA}}
$$

Figure 4 shows the general nature of the variation of average static pressure along the length of the diffuser for various Re and for a FSA of $20^{\circ}$ and $\mathrm{L}_{\mathrm{f}}^{*}$ of 0.8 . The corresponding streamlines has been shown Figure 5. It is observed that the average static pressure steeply drops at the throat and thereafter the pressure again rises. The drop is due to the fact that across the throat region, there is an abrupt change in the cross-sectional area of the diffuser. This increases the denominator of equation (iv) to an extent that even a static pressure recovery in this region cannot adequately compensate and hence the steep pressure drop. At the postthroat region, the numerator of equation (4) is influenced by both positive pressure zone (created by the fluid in the mainstream that does not undergo recirculation) and negative pressure zone (created by recirculating fluid). Initially in the post-throat region, the overall cross-sectional area of the recirculating bubble is high and so the static pressure rise is small. Further downstream there is more positive pressure and also increased kinetic energy diffusion and so the static pressure rises resulting in significant pressure recovery. It is also observed that due to a sudden drop in the cross-sectional area at the section where the fence is located, there is a sudden increase in the average static pressure at this section. Thereafter the pressure keeps increasing and after a certain maximum pressure, there is a drop in the average static pressure as the viscous dissipative effects supersede at this stage. Also, the graphs reveal that for lower Re flows, there is a quicker increase, in terms of distance along the axis, in static pressure in the post-throat region i.e. the peak average static pressure point is progressively shifted to the right as the Re increases; however the pressure recovery is more for comparatively higher Reynolds number. The quicker increase in average static pressure for lower Reynolds number is because the recirculating bubble for these cases is lesser in dimensions than the cases with higher Reynolds number. The pressure recovery for relatively higher Reynolds number flows is more because of higher diffusion. It is quite natural that the size of the recirculating bubble is higher at higher Reynolds number due to higher diffusion. Here, the presence of the fence again causes increased diffusion of fluid kinetic energy and there is a more chance of another recirculating bubble after the fence. The size of second recirculation bubble after the fence increases with Reynolds number, shown in Figure 5. For relatively higher Re flows, the size of the recirculating bubble is more and the presence of the fence causes increased diffusion of fluid kinetic energy. This may cause the rise in the static pressure.

Figures 6(a) and 6(b) show the general variation of average static pressure along the length, for different $L_{f}{ }^{*}$ at $F S A$ of $10^{\circ}$ and for Reynolds number of 20 and 100 respectively. The corresponding streamline contours have been shown in Figure 7(a) and 7(b) respectively. From Figure 6(a), it is observed that at low Reynolds number, sharp pressure drop persists at the fence zone.

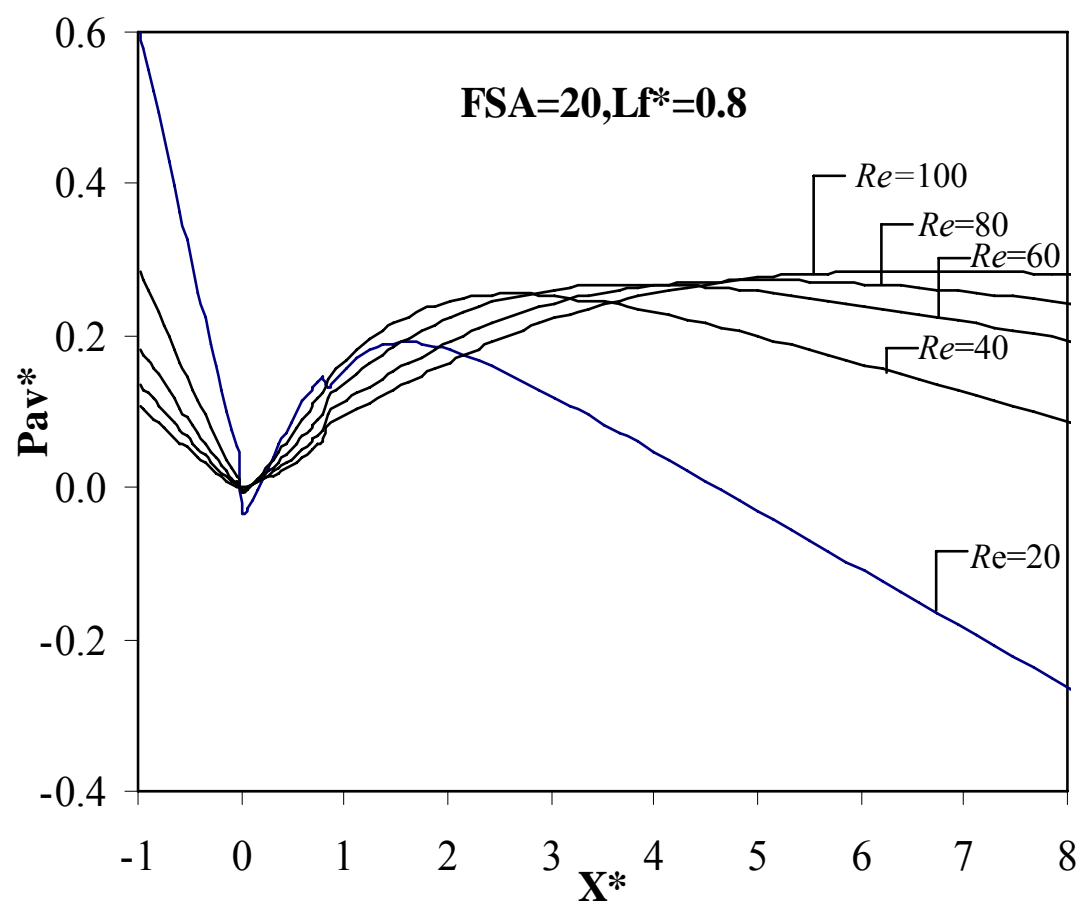

Figure 4. Variation of average static pressure with axial distance for different Reynolds numbers.

Whereas at relatively high Reynolds number (Figure 6(b)), no such drop has been observed, instead, pressure recovery is noted. It may be due to that at lower Reynolds number flows; the fluid has a greater tendency to catch the walls of the diffuser, when compared to higher Reynolds number flows. From Fig 6(a), i. e., at lower Reynolds number, it is noted that maximum average 
static pressure rise in the computational domain occurs after the fence for $L_{f}^{*}$ of 0.2 and 0.8 . This rise is less compared to simple sudden expansion without fence. Whereas, for $L_{f}{ }^{*}$ from 1.4 to 2.6 , the maximum static pressure rise occurs at the upstream of fence. The average static pressure rise after the fence is less for $L_{f}{ }^{*}$ of 2.0 and 2.6 compared to simple sudden expansion without fence.
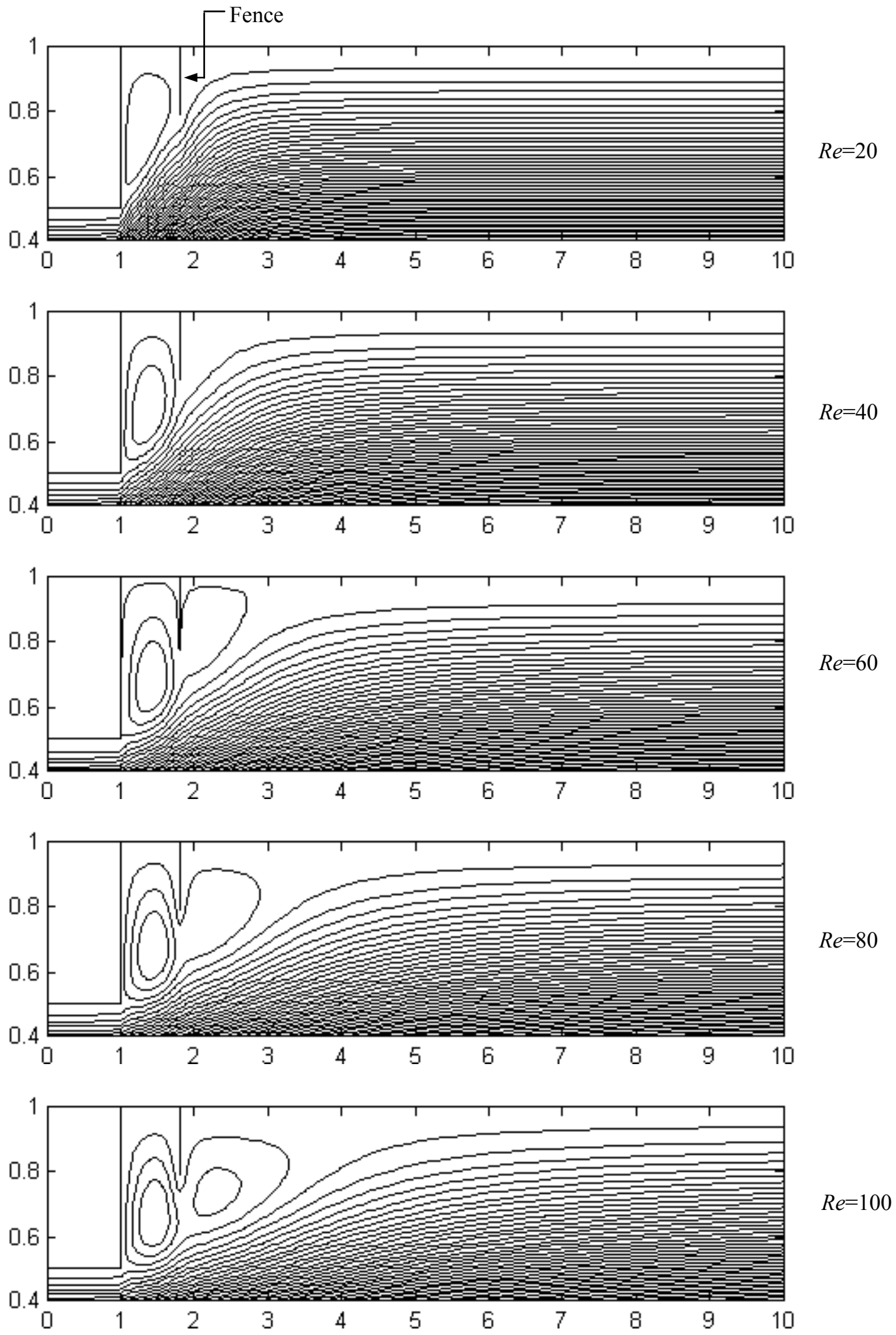

Figure 5. Streamlines for different Reynolds numbers at ${L_{f}}^{*}=0.8, F S A=20$. 


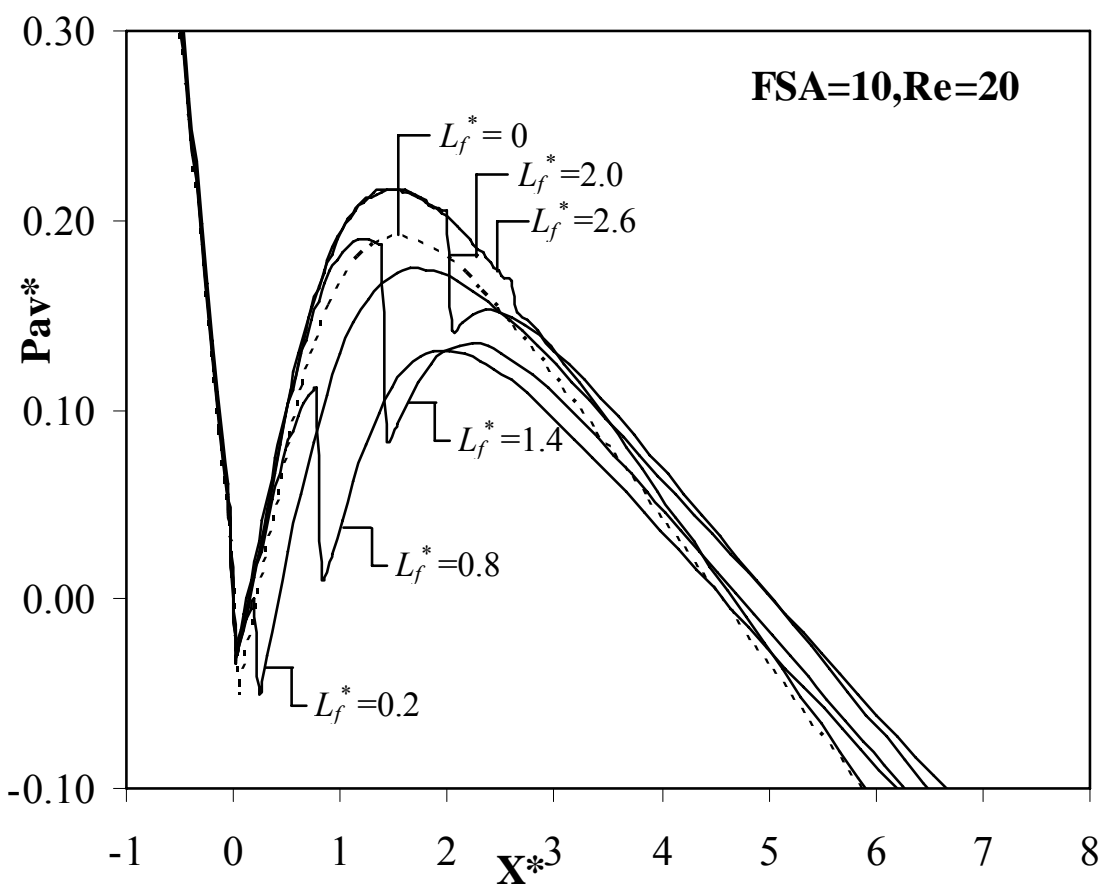

Figure 6(a). Effect of $L_{f}{ }^{*}$ on average static pressure at $F S A=10, R e=20$.

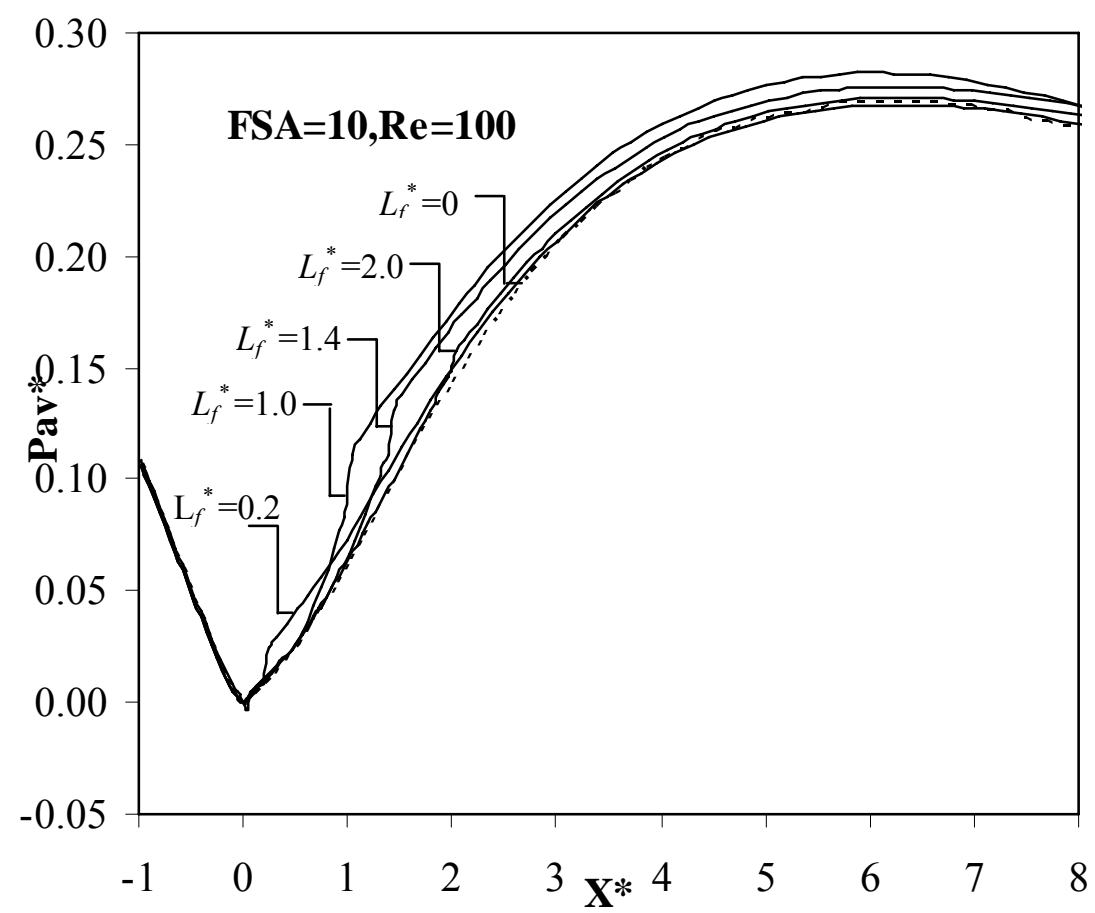

Figure 6(b). Effect of $L_{f}{ }^{*}$ on average static pressure at $F S A=10, R e=100$. 

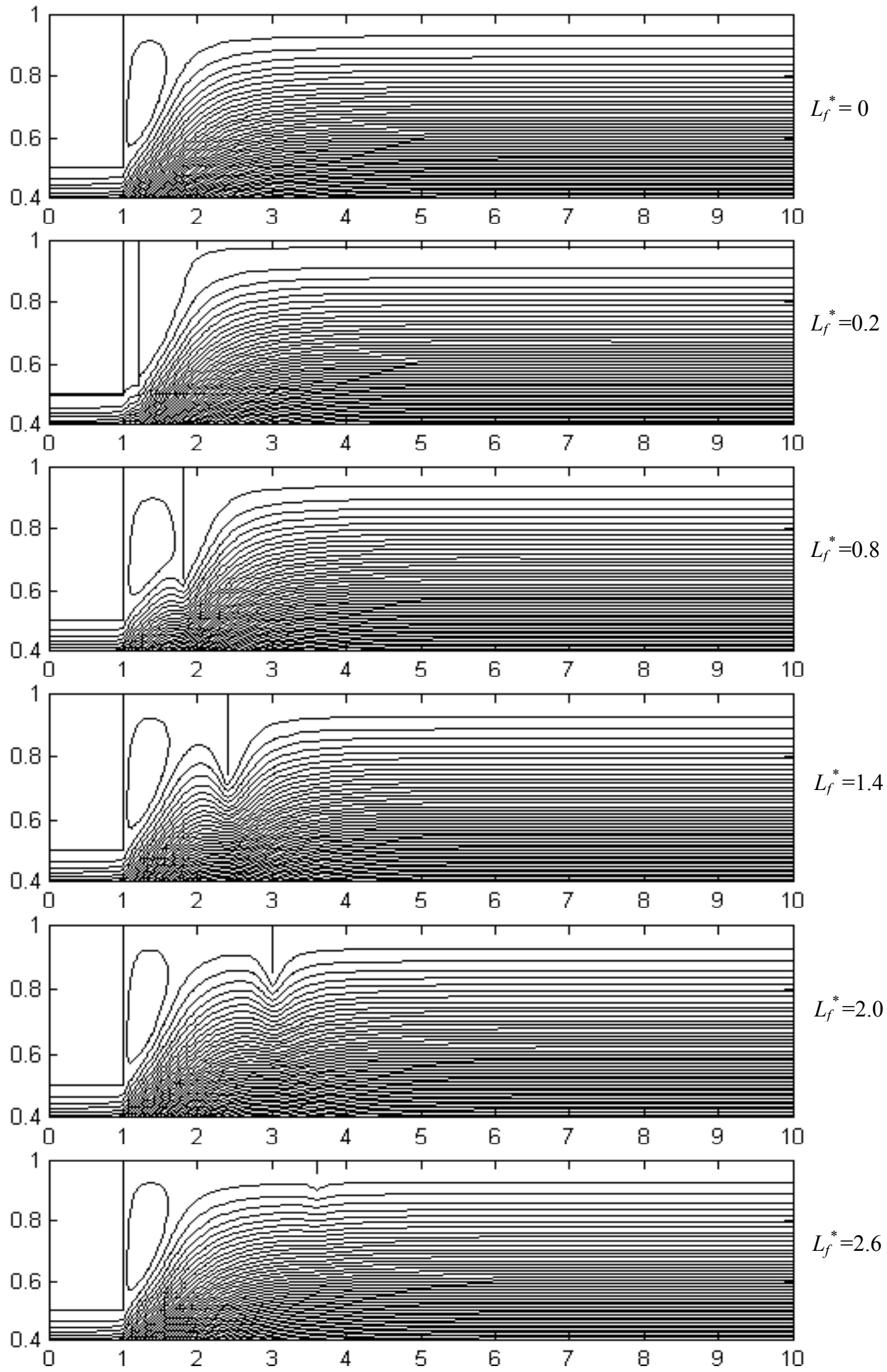

Figure 7(a). Streamline contours for different $L_{f}{ }^{*}$ at $F S A=10, R e=20$. 

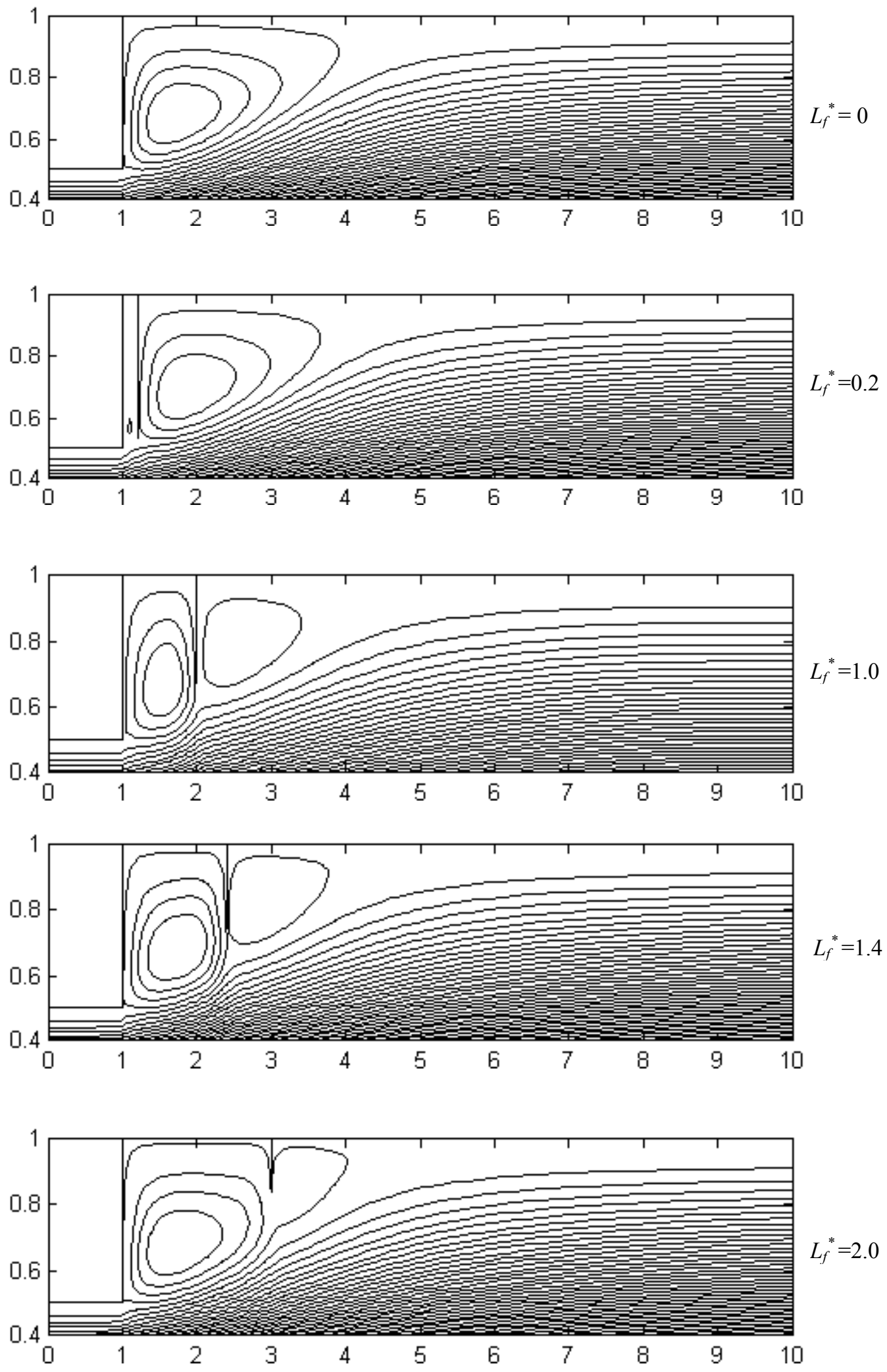

Figure 7(b). Streamline contours for different $L_{f}{ }^{*}$ at $F S A=10, R e=100$. 


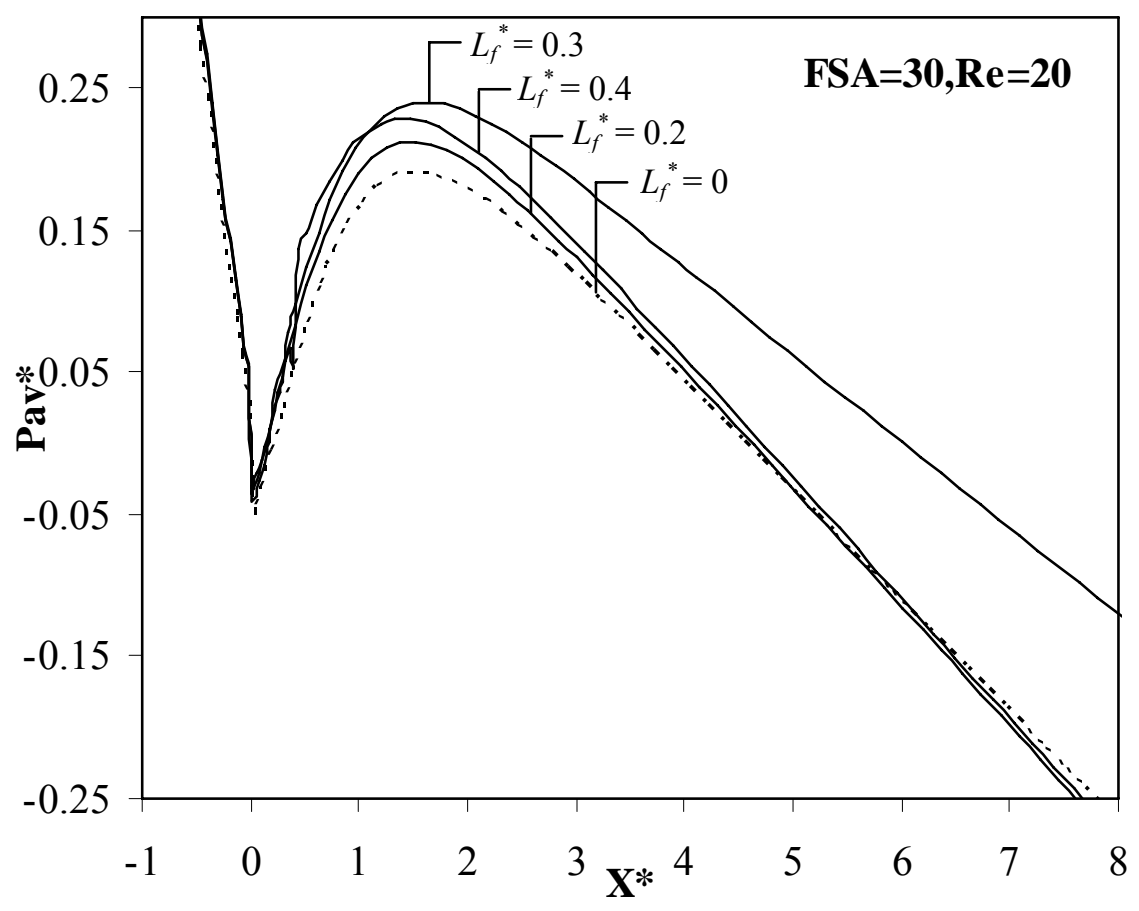

Figure 8(a). Effect of $L_{f}{ }^{*}$ on average static pressure at $F S A=30, R e=20$.

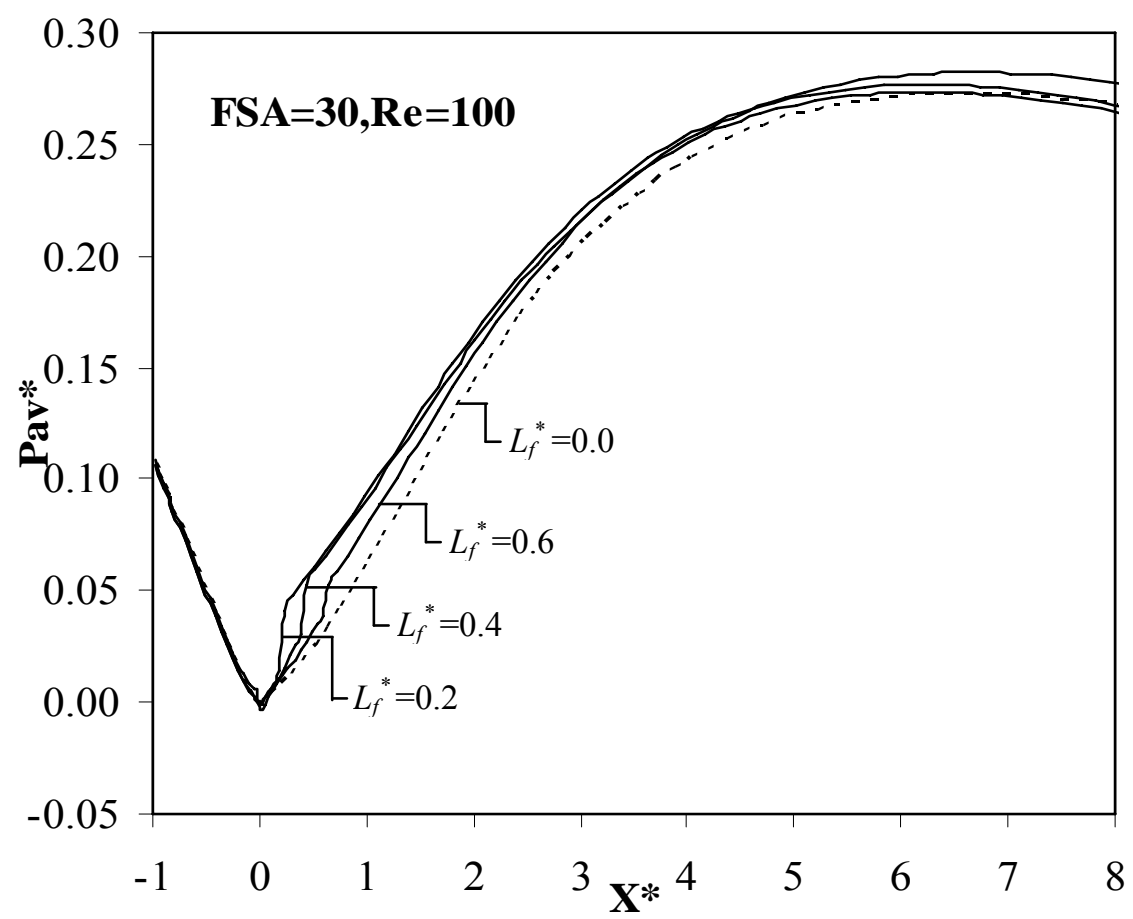

Figure 8(b). Effect of $L_{f}{ }^{*}$ on average static pressure at $F S A=30, R e=100$. 


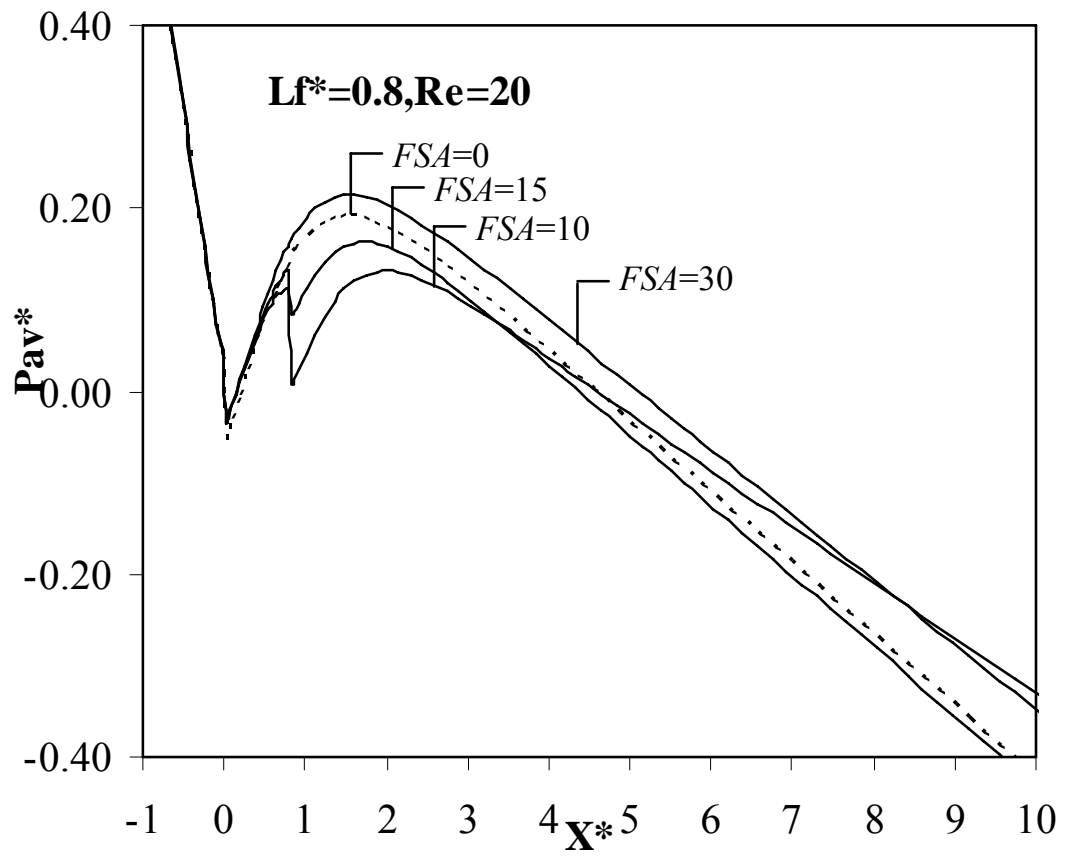

Figure 9(a). Effect of FSA on average static pressure at $L_{f}{ }^{*}=0.8, R e=20$.

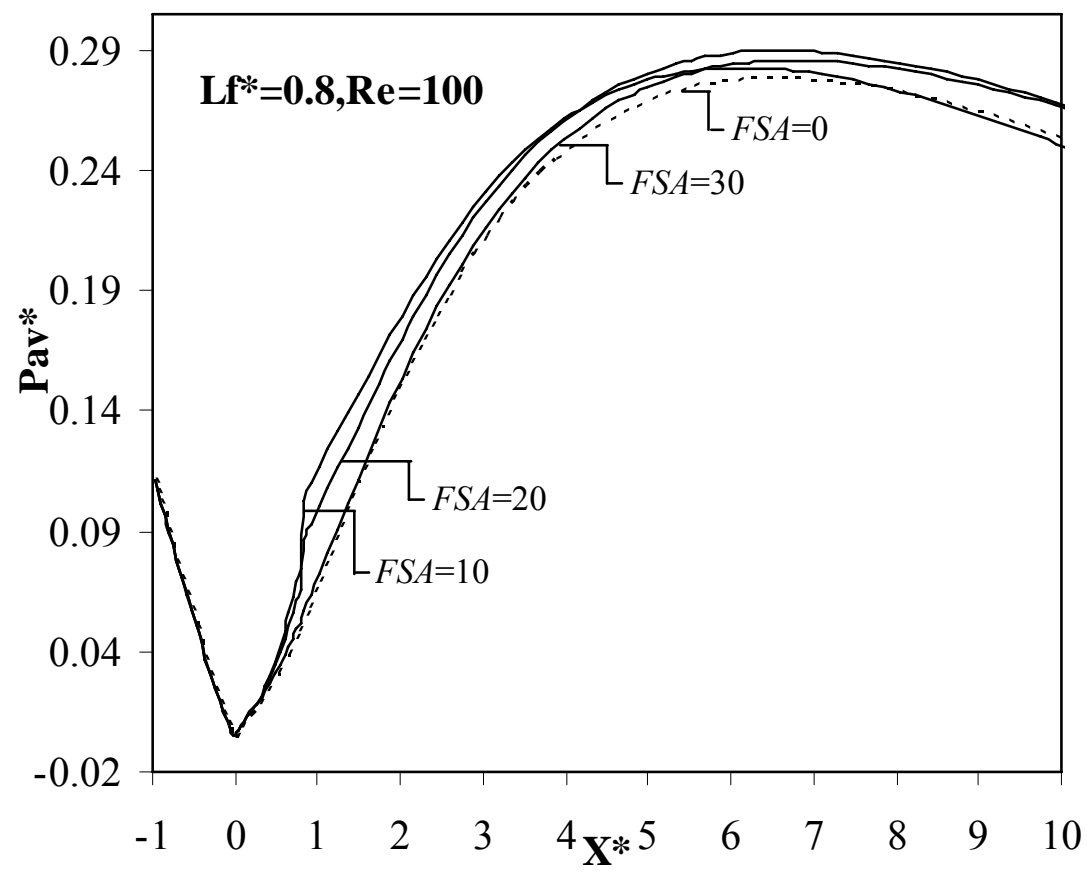

Figure 9(b). Effect of $F S A$ on average static pressure at $L_{f}{ }^{*}=0.8, R e=100$. 
This situation actually highlights that the main objectives of using the fence becomes futile. The reason behind the observations may be explained with Figure 7(a). In Figure 7(a), at $L_{f}{ }^{*}=0.2$, it can be said that the configuration will act more or less as simple sudden expansion, because the distance between the throat and fence is minimum. For $L_{f}{ }^{*}=0.8$, the distance has increased to some extent, which enables higher diffusion in that zone causing more pressure rise at the location of the fence in comparison to the case $L_{f}{ }^{*}=0.2$. In case of streamlines contours for $L_{f}{ }^{*}=1.4,2.0$ and 2.6, it is observed that as $L_{f}{ }^{*}$ increases, the chance of diffusion in between throat and fence increases. But after the fence, the pressure rise due to diffusion is less because in decrease in height of the fence with the increase in $L_{f}{ }^{*}$. More diffusion in between throat and fence for the $L_{f}{ }^{*}$ of 2.0 and 2.6 compared to the simple sudden expansion may be the cause of high pressure rise. So, from the perspective of diffuser, presence of fence at low Reynolds number and low FSA is not beneficial. For Reynolds number of 100 (Figure 6(b)), the maximum value of average static pressure after fence increases with $L_{f}{ }^{*}$ upto a certain value of $L_{f}{ }^{*}$, then it decreases. The static pressure rise with fence at relatively higher Reynolds number is always higher compared to simple sudden expansion. Maximum value has been observed at $L_{f}{ }^{*}=1.0$. So, at low FSA, sudden expansion with fence will be beneficial by increasing Reynolds number. From Figure 7 (b), the streamline contours depict that as the $L_{f}{ }^{*}$ increases initially, the diffusion in between the throat and fence and the post fence zone increases. After achieving some maximum value of the static pressure it decreases due to higher viscous effect.

Further, the authors became interested to study the effect of $L_{f}{ }^{*}$ on average static pressure at Reynolds number of 20 and Reynolds number of 100. At FSA of $30^{\circ}$, these are shown in Figure 8(a) and 8(b). From Figure 8(a), it is noted that incorporation of fence first increases the maximum average static pressure upto certain $L_{f}{ }^{*}$, then decreases. So, by putting fence, benefit can be obtained at low Reynolds number by increasing FSA. At higher FSA and comparatively higher Reynolds number (Figure 8(b)), similar nature of variation of maximum average static pressure has been observed like Figure 6(b), and Figure 8(a). So, relatively higher Reynolds number with higher FSA always will give more benefit by using fence. The probable reasons have been explained earlier in respect of Figure 6(b) and 7(b).

Figures 9 (a) and 9 (b) show the variation of average static pressure along the length for the $R e$ of 20 and 100, for a typical value of $L_{f}{ }^{*}=0.8$ and varying the $F S A$ from $0^{\circ}$ to $30^{\circ}$. It is seen that for lower Re and lower $F S A$, there is a sudden drop in pressure in the vicinity of the fence; however this effect reduces and finally becomes negligible as the FSA is increased. As mentioned before, flows with lower $R e$ have a much greater tendency of adhering to the walls of the diffuser thereby causing a smaller eddy formation. It is to be noted that for a fixed $L_{f}^{*}$ and variable $F S A$, the height of the fence changes. As the FSA increases, there is a greater area for fluid flow and hence the pressure drop reduces. The opposite happens for relatively higher Reynolds numbers i.e., instead of drop in pressure (in the vicinity of fence), the enhancement of pressure is taking place in the vicinity of fence. This is because, as Re increases, the dimensions of the recirculating bubble are more, causing more diffusion. In fact, for such cases, the initial pressure rise in the post throat region is more for the cases where the fence is incorporated. This spatial rate of pressure rise is because of higher diffusion of fluid kinetic energy for the cases where fence is incorporated.

For the Figures 9(a) and 9(b), two distinct cases are easily observable. One is for lower Reynolds number and the other is for relatively higher Reynolds number. Again each of these can be subdivided into two categories based on the influence of FSA. For the $L_{f}^{*}$ considered, when the FSA has lower values and the flows have lower Reynolds number, the figures show that for sudden expansion without fence offers more benefit than sudden expansion with fence as far as maximum pressure rise is concerned. However, at this lower Reynolds number, as FSA increases keeping $L_{f}^{*}$ constant, the magnitude of the static pressure rise increases gradually and finally it becomes greater than simple sudden expansion situation. In other words, for lower $R e$, keeping $L_{f}^{*}$ constant, a proper choice of FSA ensures that sudden expansion with fence can be made to be always more effective than simple sudden expansion. On the other hand, for relatively higher Reynolds numbers, it is observed that sudden expansion with fence is always more effective than sudden expansion without fence although there is a deterioration in the average static pressure rise as the FSA increases beyond a certain value, this being subject to the choice of $L_{f}^{*}$. Thus it can be seen that there is a significant influence of both $R e$ and in particular, the FSA, on the static pressure recovery.

\subsection{Diffuser effectiveness}

To quantify the performance of a diffuser, the maximum static pressure rise in the diffusion zone may be considered to be the prime factor. Therefore, the effectiveness of the diffuser may be defined as the maximum rise in static pressure with respect to ideal diffusion process. In our study, the computations for the diffuser effectiveness have been performed using the following nondimensional expressions as developed by Chakrabarti et al. (2003):

$$
\eta_{d}=\frac{2\left(p_{2}{ }^{*} \text { avg }-p_{1}{ }^{*} \text { avg }\right)_{\text {measured }}}{1-\frac{1}{(A R)^{2}}}
$$

where, $\mathrm{p}_{1 \text {.avg }}^{*}$ is the average value of static pressure at throat and is obtained by linear interpolation of the pressures at the nodes just before and after the throat, and $\mathrm{p}_{2 \text {.avg }}^{*}$ is the maximum average static pressure achieved after the fence. 
Figure 10 describes the variation of diffuser effectiveness with Reynolds number for a particular $L_{f}{ }^{*}$ of 0.8 and variable $F S A$. The first observation is that initially there is a rapid change in diffuser effectiveness as the Reynolds number increases and thereafter the effectiveness curve exhibits near asymptotic behavior. Hence we conclude that the diffuser effectiveness does not change appreciably in relatively higher Reynolds number regime. The initial rapid increase in effectiveness is because, as $R e$ increases, the diffusion of kinetic energy into the development of static pressure head also increases. This gain is considerably greater than the eddy losses. Even at higher Reynolds number the diffusion of kinetic energy occurs but the gains are offset by the eddy losses. Thus at higher Reynolds number, the curves for effectiveness show asymptotic behavior. The computations have also revealed that, for the $L_{f}{ }^{*}$ considered, at higher Reynolds number, sudden expansion with fence offers more benefit than that of a simple case of sudden expansion $(F S A=0)$. At lower Reynolds number, for the considered $L_{f}^{*}$, if the $F S A$ is kept low, the fence offers no benefit towards the diffuser effectiveness; rather the fence reduces effectiveness. But for higher values of $F S A$, the same $L_{f}{ }^{*}$ value causes the fence to augment the diffuser effectiveness even for lower Reynolds number. These observations show that the FSA influences the diffuser effectiveness for all Reynolds numbers.

At this point, authors have become interested to study the effect of $L_{f}^{*}$ on diffuser effectiveness for different Reynolds numbers. Figures 11(a) and 11(b) show the general variation of diffuser effectiveness with $L_{f}^{*}$ for an $F S A$ of $10^{\circ}$ for the Reynolds number varying from 20 to 100. At lower value of Reynolds number, (Figure 11(a)), it is noted that diffuser effectiveness decreases by putting fence upto a certain value of $L_{f}^{*}$, then it increases. The probable reason of decreasing the diffuser effectiveness may be that more frictional loss at low Reynolds number due to adhering flow. After achieving some value of $L_{f}{ }^{*}$, this frictional force reduces as the height of the fence decreases and effectiveness increases accordingly. From the figure 11(b), it is seen that at comparatively higher Reynolds numbers, at a particular magnitude of $L_{f}{ }^{*}$, there is a peak value of diffuser effectiveness. After the peak value, the drop in effectiveness is observed. The probable reason may be due to greater length of primary recirculating bubble for higher $L_{f}^{*}$. Greater dimension of this eddy causes more frictional dissipation and finally reduces the effectiveness.

Figures 12(a) and 12(b) show the impact of FSA on Reynolds number of 20 and Reynolds number 100 respectively. Our earlier observation (Figure 11(a)) is that diffuser effectiveness decreases first and then it's magnitude increases with increase of $L_{f}{ }^{*}$ at $F S A$ of $10^{\circ}$ and Reynolds number of 20. Here in the Figure 12(a), the similar nature has been noted in case of $F S A$ of $15^{\circ}$ and $20^{\circ}$ also. But the reverse nature is observed for higher $F S A$ of $25^{\circ}$ and $30^{\circ}$, that the diffuser effectiveness increases initially and then it's magnitude decreases with $L_{f}^{*}$. The probable reason may be that, at higher FSA, at first the frictional loss decreases as the height of the fence decreases, then at higher $L_{f}{ }^{*}$, more eddy loss takes place for larger recirculating bubble. The results of the study on the effect of $L_{f}^{*}$ and fence subtended angle on diffuser effectiveness at relatively higher Reynolds number of 100 has been shown in Figure 12(b). From the figure, it is observed that each curve of a particular value of FSA is having maximum magnitude of effectiveness at a value of $L_{f}^{*}$. This value of $L_{f}^{*}$ for maximum diffuser effectiveness varies from FSA to $F S A$. Therefore, maximum effectiveness can be obtained at higher $F S A$ with higher Reynolds number with selective $L_{f}^{*}$.

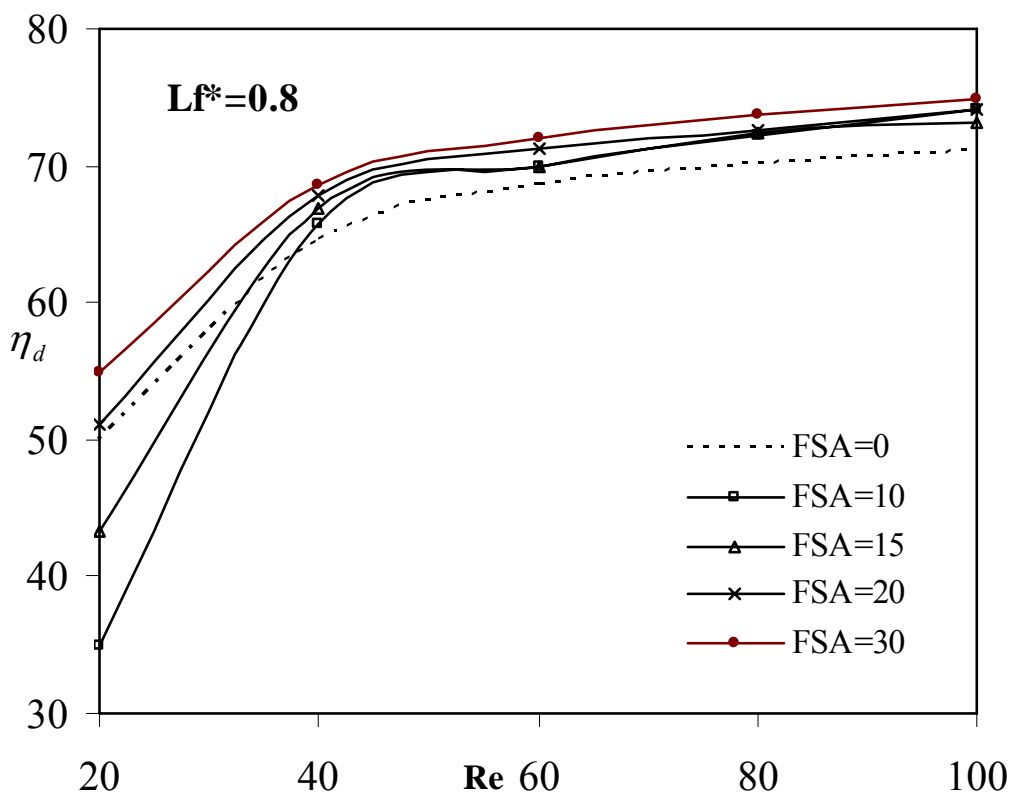

Figure 10.Variations of $\eta_{d}$ with $\operatorname{Re}$ for different $F S A$ at $L_{f}{ }^{*}=0.8$. 


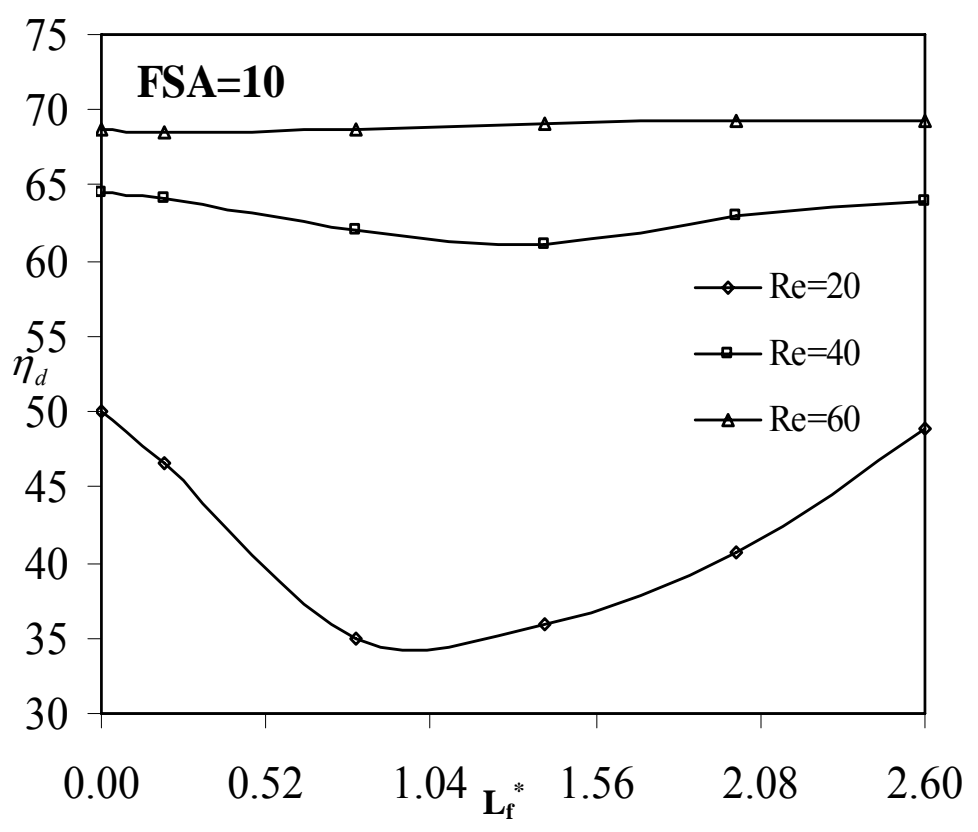

Figure 11(a).Variations of $\eta_{d}$ with $L_{f}{ }^{*}$ for different low $R e$ at $F S A=10$.

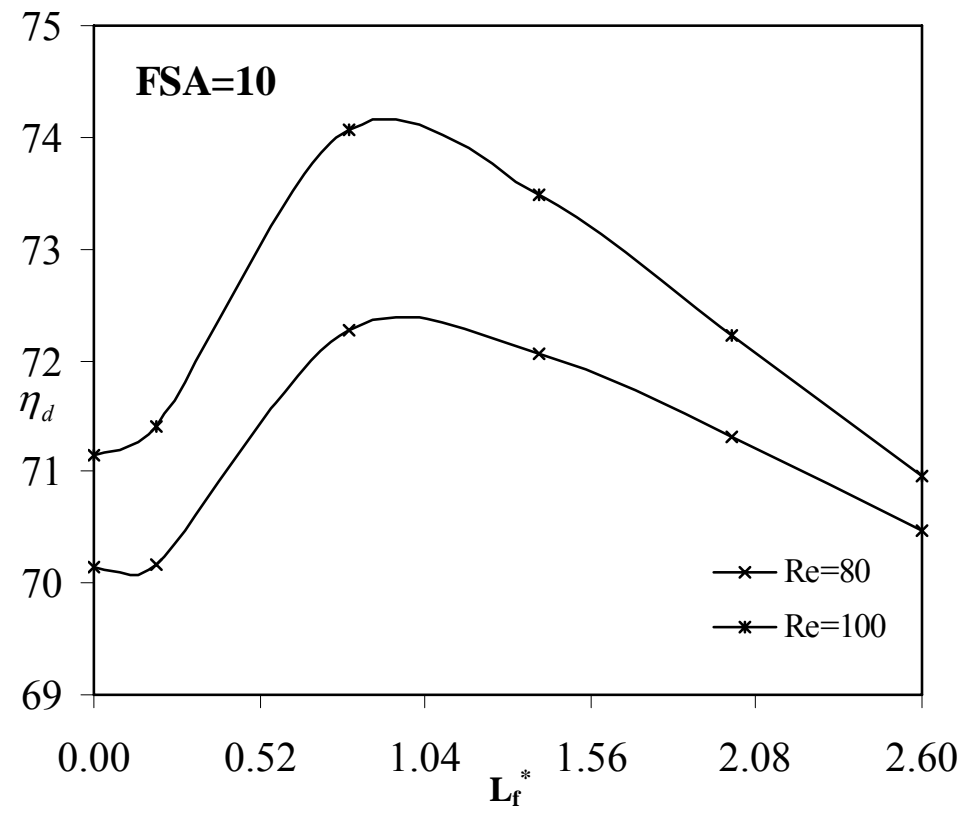

Figure 11(b).Variations of $\eta_{d}$ with $L_{f}{ }^{*}$ for different higher $R e$ at $F S A=10$. 


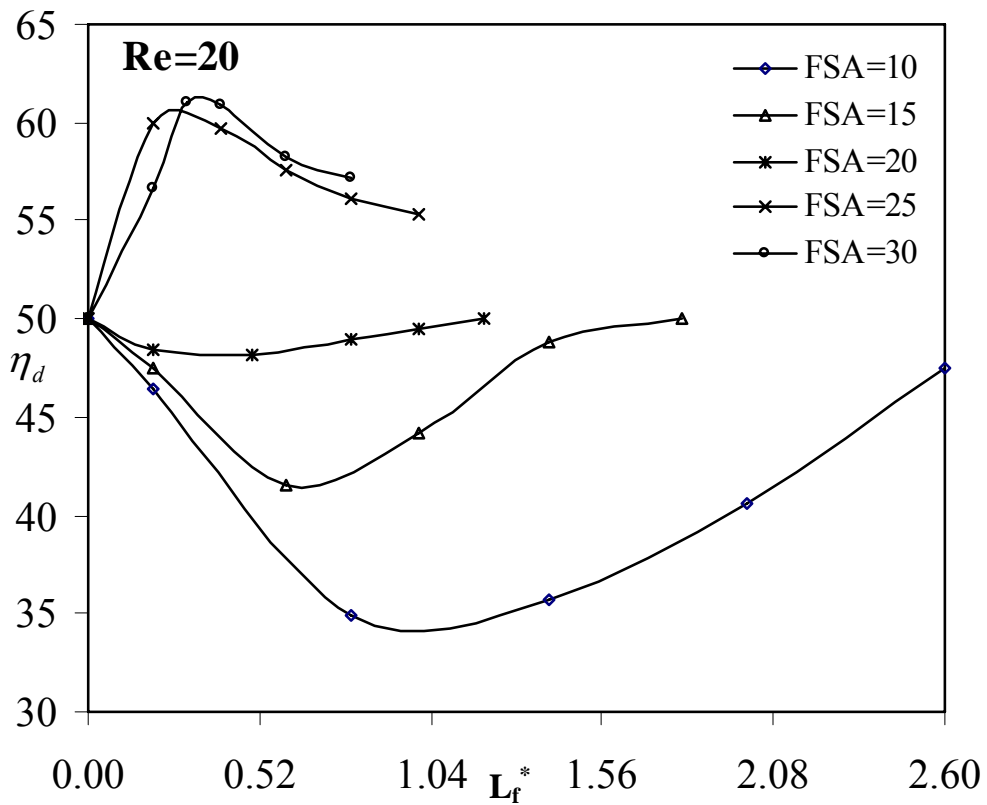

Figure 12(a).Variations of $\eta_{d}$ with $L_{f}{ }^{*}$ for different $F S A$ at $R e=20$.

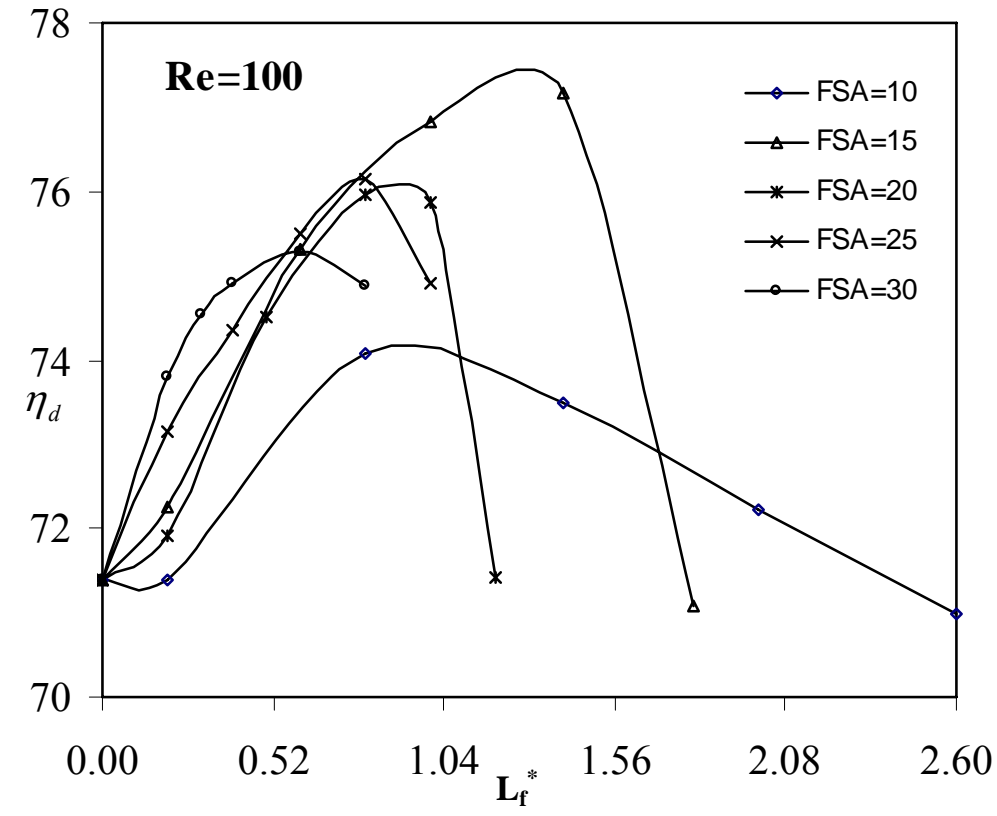

Figure 12(b).Variations of $\eta_{d}$ with $L_{f}{ }^{*}$ for different $F S A$ at $R e=100$.

\subsection{Distance of Maximum Average Static Pressure Rise from Throat}

The primary reason of adopting a sudden expansion configuration is to achieve maximum pressure rise in the shortest possible space. The distance $\left(L p^{*}\right)$ between the throat and the location of maximum average static pressure after the fence, measured along the diffuser length, is an important parameter in the design of an effective diffuser. This distance is an important aspect in the 
design since it can be considered to be the effective length of the diffuser within which the diffusion process brings about maximum possible static pressure rise.

The variations of $L p{ }^{*}$ with $R e$ for different $F S A$ at $L_{f}{ }^{*}=0.8$ has been shown by Figure 13 . The computational results show that, for a particular $L_{f}^{*}$, as $R e$ increases, the distance of maximum static pressure rise from the throat also increases linearly. This shows that the $L_{p}{ }^{*}$ for sudden expansion with and without fence are more or less same. Further, Figure 14 shows that, when FSA is constant, then, at a particular value of $R e$, the values of $L_{p}{ }^{*}$ remain more or less constant for all considered $L_{f}{ }^{*}$. These observations suggest that the Reynolds number is the most important parameter in deciding the magnitude of $L_{p}{ }^{*}$. This can be explained by the fact that the recirculating zone and the zone containing the main fluid are separated by a divider streamline which stagnates on the outer wall of the diffuser whose location is dictated by the flow Reynolds number. Hence, once the location of the stagnation point of the divider streamline is fixed by the value of $R e$, the variation in $L_{f}^{*}$ gives variation in average static pressure rise but the location of maximum pressure does not vary significantly. For higher Reynolds numbers, as previously discussed, there is a value of $L_{f}{ }^{*}$ corresponding to a particular FSA where the diffuser effectiveness is maximum. Further, for this $L_{f}^{*}$, the value of $L_{p}{ }^{*}$ is more or less same in comparison to a simple sudden expansion configuration. Therefore it can be concluded that the magnitude of $L p^{*}$ will remain more or less same irrespective of $F S A$ and $L_{f}^{*}$, when $R e$ is fixed, only the diffuser effectiveness will be affected.

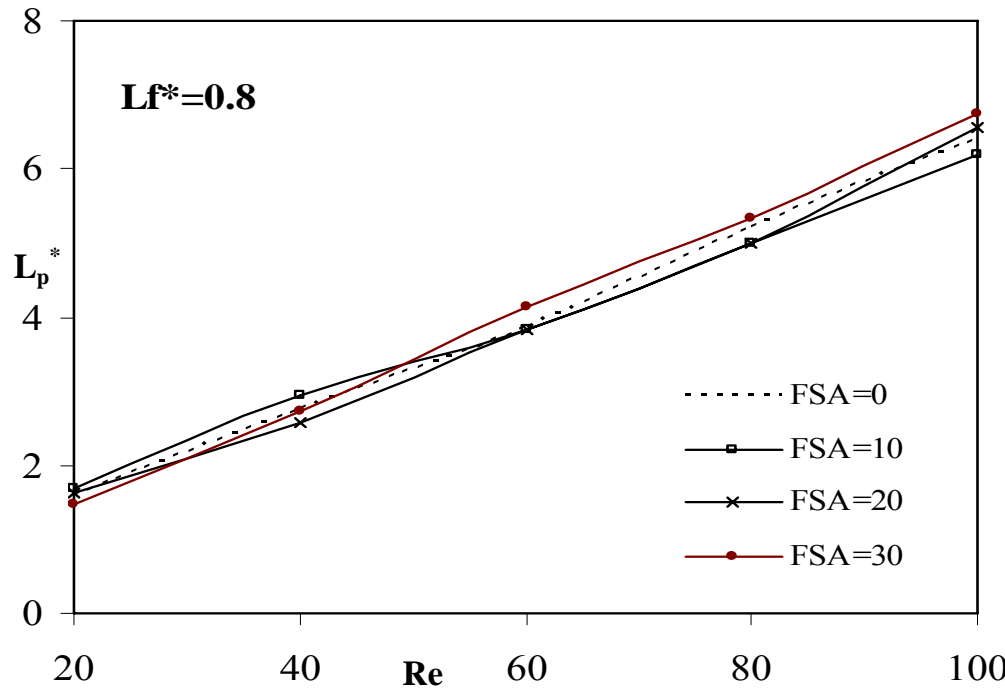

Figure 13.Variations of $L_{p}{ }^{*}$ with Re for different $F S A$ at $L_{f}{ }^{*}=0.8$.

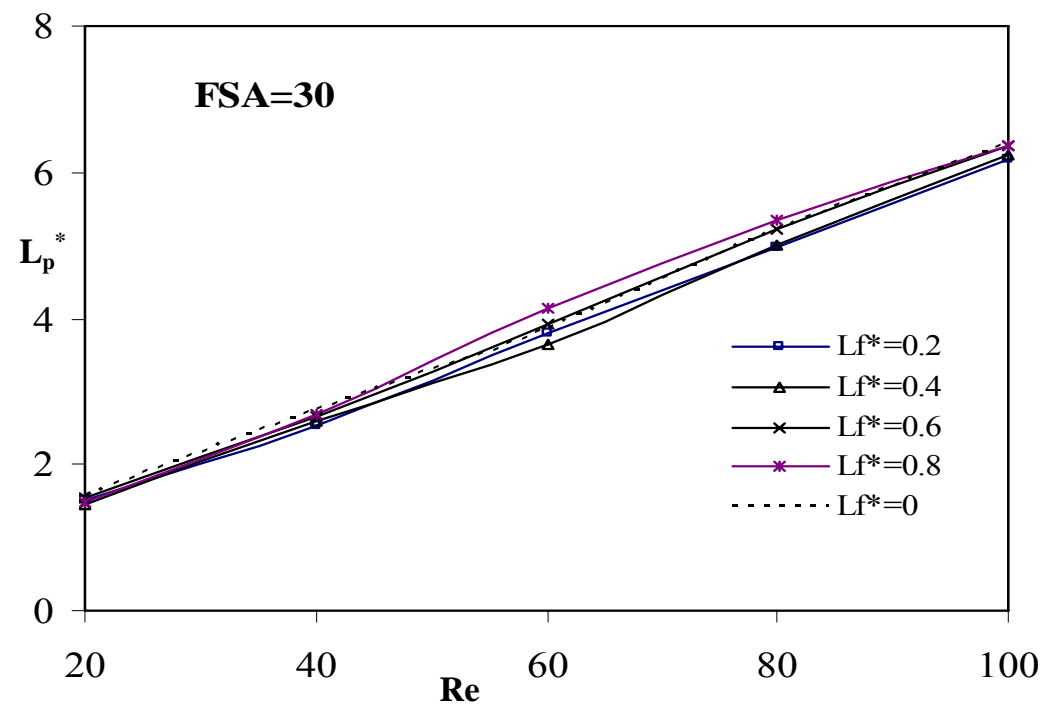

Figure 14.Variations of $L_{p}{ }^{*}$ with $\operatorname{Re}$ for different $L_{f}{ }^{*}$ at $F S A=30$. 


\subsection{Variation of average stagnation pressure}

Stagnation pressure is one of the important parameters to determine the performance of the various components of a gas turbine cycle as well as the cycle itself. The computation of average stagnation pressure at any section should take into considerations of the direction of the velocity vector particularly in a flow situation, like the present case where the flow is the recirculating type. After performing the energy balance, Chakrabarti et al. (2003) have developed the following mathematical formulation to estimate the stagnation pressure at a particular cross section and this has been used in the present study;

$$
p_{\text {sav }}=\frac{\int_{A_{e}}\left(p_{e}+\frac{1}{2} \rho{\overline{V_{e}}}^{2}\right) u_{e} d A_{e}}{\int_{A_{e}} u_{e} d A_{e}}
$$

where the subscript 'e' refers to the plane of measurement.

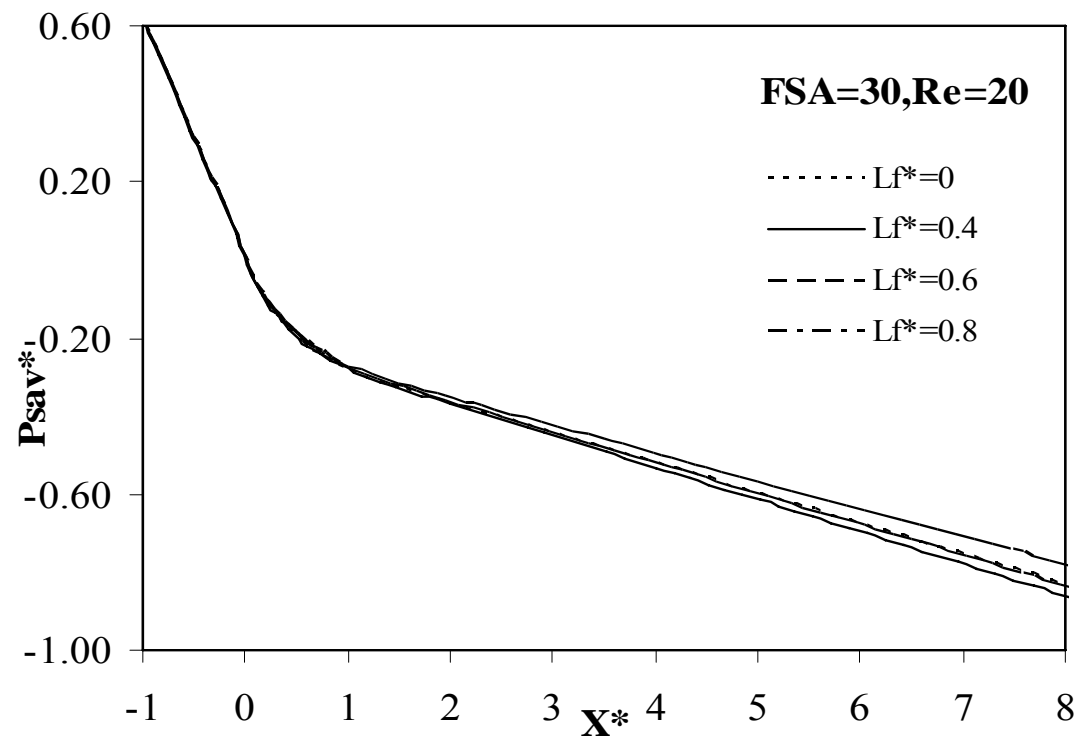

Figure 15(a). Effect of $L_{f}{ }^{*}$ on average stagnation pressure at $F S A=30, R e=20$.

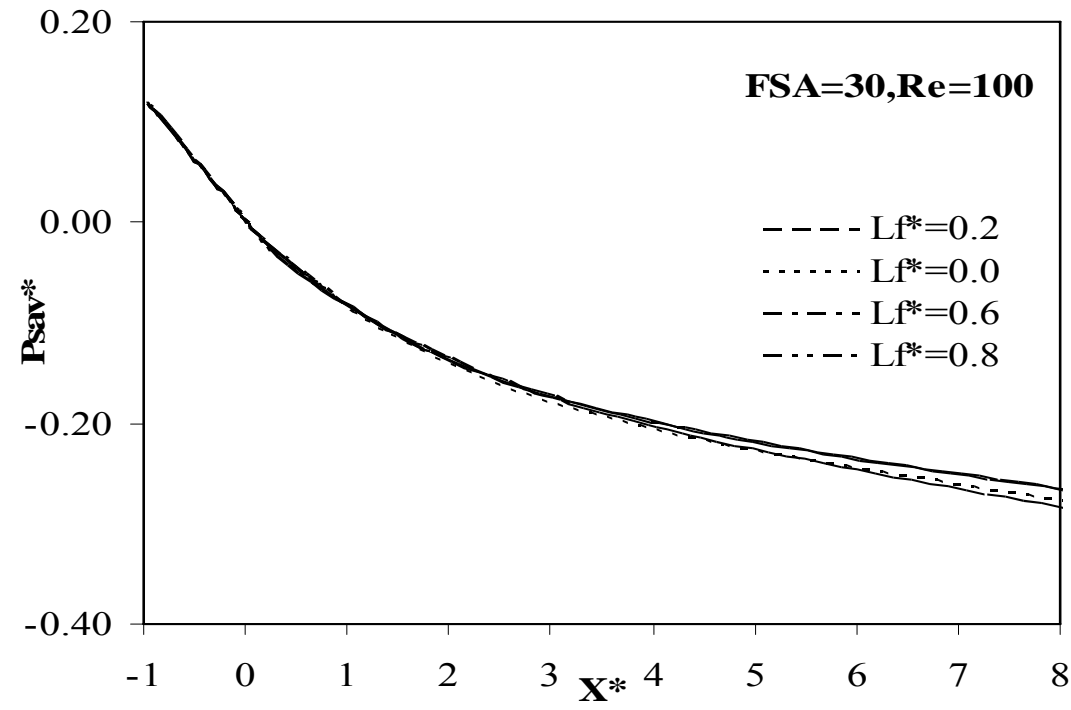

Figure 15(b). Effect of $L_{f}{ }^{*}$ on average stagnation pressure at $F S A=30, R e=100$. 
Figures $15(a)$ and 15 (b) show the variations of average stagnation pressure along the length of the diffuser for different $L_{f}^{*}$ and typically for Reynolds numbers of 20 and 100 respectively at $F S A$ of $30^{\circ}$. As expected, there is a gradual decrease in the average stagnation pressure due to viscous dissipative effects. It is also observed that, higher the Reynolds number, lesser is the corresponding pressure drop. This, as explained before, is because at low Reynolds number, the flow will have a greater tendency to 'catch' the surface of the outer duct much faster than flows with higher Re. The magnitude of stagnation pressure drop is more or less same for all considered $L_{f}^{*}$. So, Reynolds number is the prime factor to control the stagnation pressure drop. Figures 16(a) and 16(b) show the impact of $F S A$ on stagnation pressure drop at low $R e$ and high $R e$. From these figures, it is also noted that there is no much impact of FSA on stagnation pressure drop. Therefore, the incorporation of fence in sudden expansion is having no appreciable impact on stagnation pressure drop in comparison to the case of sudden expansion configuration.

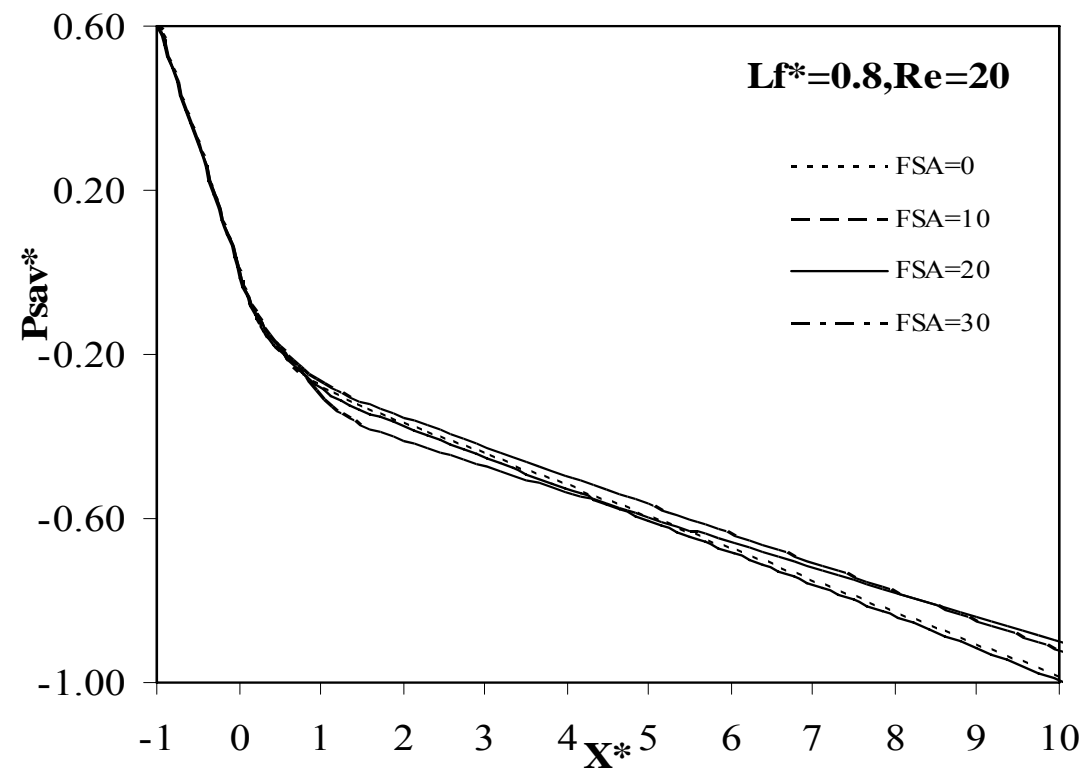

Figure 16(a). Effect of FSA on average stagnation pressure at $L_{f}{ }^{*}=0.8, R e=20$.

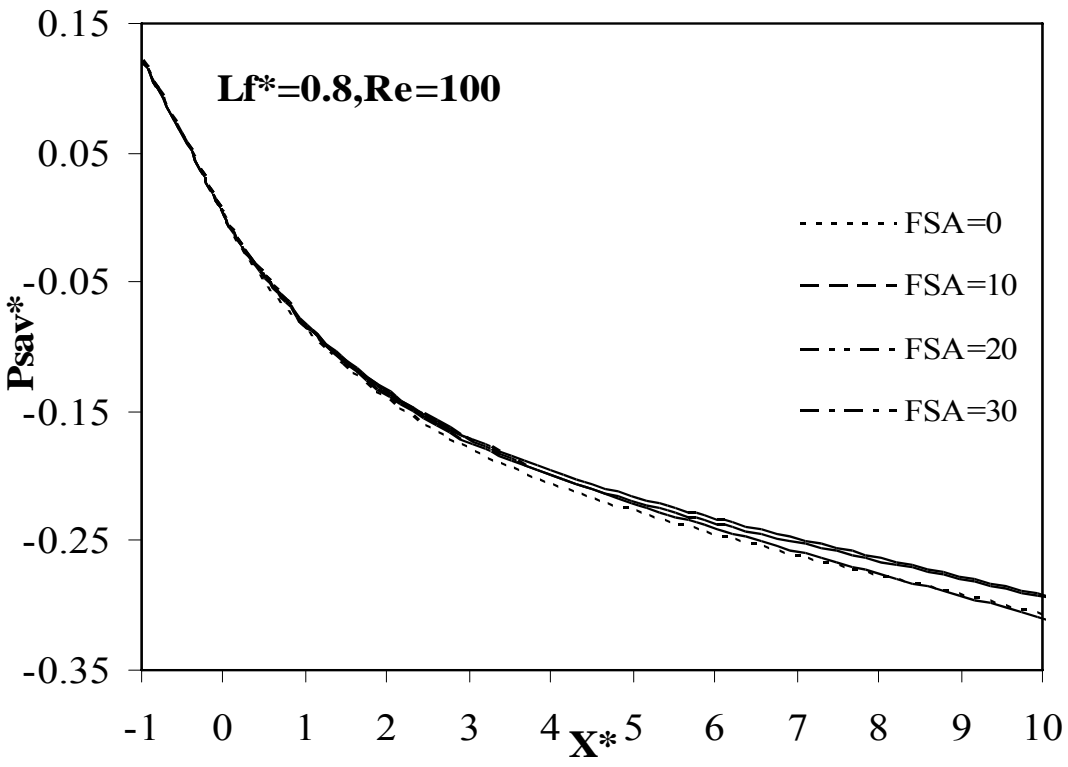

Figure 16(b). Effect of $F S A$ on average stagnation pressure at $L_{f}{ }^{*}=0.8, R e=100$. 


\section{Conclusions}

In the present study, performance analysis of a sudden expansion with fence for an aspect ratio of 2 has been carried out. The Reynolds number is in the range of 20 to 100 and the fence subtended angle between $10^{\circ}$ to $30^{\circ}$. The location of fence from throat varies from 0.2 to 2.6. The effects of fence subtended angle, location of the fence from the throat and Reynolds number on typical diffuser properties have revealed several features. The observations are summarized below:

a. The average static pressure rise typically depends on both $L_{f}^{*}$ and $F S A$ apart from the dependence on Reynolds number.

b. In comparison to simple sudden expansion, the performance of a sudden expansion with fence always offers better benefit for relatively higher Reynolds number at any value of FSA.

c. At comparatively higher Reynolds numbers, to achieve the maximum static pressure rise and maximum diffuser effectiveness, the location of the fence from the throat is to be fixed depending on the value of FSA.

d. When Reynolds numbers are on the lower side, then, at lower $F S A$, sudden expansion with fence does not always offer higher benefits with respect to sudden expansion without fence; the benefits typically depend on both $L_{f}^{*}$ and $F S A$. But for higher $F S A$, even at lower $R e$, the fence offers more benefit.

e. The effective length of the sudden expansion with and without fence, viewed as a diffuser, increases more or less linearly with increase in Reynolds number irrespective of any $F S A$ and $L_{f}^{*}$.

f. At a particular value of Reynolds number, the $F S A$ and $L_{f}^{*}$ have no impact on the effective length of the diffuser.

g. As far as the average stagnation pressure drop is concerned, it decreases with increase in Reynolds number at a particular value of $F S A$ and $L_{f}^{*}$. FSA and $L_{f}^{*}$ have no impact on the average stagnation pressure drop.

The future work in this regard to perform three dimensional numerical flow analysis in case of transient and turbulent flow conditions with high Reynolds numbers, which are practically persisting in the diffuser used in aircraft system.

\section{References}

Adkins R. C., 1975, A short diffuser with low pressure loss, ASME J. Fluids Engg., Vol. 93, pp. 297-302.

Ahmed, W. H., Ching, Chan, Y. and Shoukri, M, 2008, Development of two-phase flow downstream of a horizontal sudden expansion, International Journal of Heat and Fluid Flow, Vol. 29,pp. 194-206.

Ainley, D. G., 1945, Investigations of Air Flow Through Some Annular Diffusers, Power Jet Report 1151.

Armaly, B. F., Durst, F., Pereira, J. C. F. and Schonung, B., 1983, Experimental and theoretical investigation of backward-facing step flow, J. Fluid Mech., Vol. 127, pp. 473-496.

Barkley, D., Gomes, M. G. M. and Henderson, R. D., 2002, Three-dimensional instability in flow over a backward-facing step, $J$. Fluid Mech., Vol. 473, pp. 167-190.

Beaudoin, J., Cadot, O., Aider, J. and Wesfreid, J., 2004, Three-dimensional stationary flow over a backward-facing step, Eur. J. Mech. B/Fluids, Vol. 23, pp. 147-155.

Blackburn, H. M., Barkley, D. and Sherwin, S. J., 2008, Convective instability and transient growth in flow over a backwardfacing step, J. Fluid Mech., Vol. 603, pp. 271-304.

Casarsaa, L. and Giannattasio, P, 2008, Three-dimensional features of the turbulent flow through a planar sudden expansion, physics of fluids, Vol. 20, pp.015103-15.

Chakrabarti S., Ray S. and Sarkar A.,2002, Numerical simulation of the performance of a vortex controlled diffuser in low Reynolds number regime, Int. J. Numerical Methods for Heat and Fluid Flow, Vol. 12, pp.224-240.

Chakrabarti S., Ray S. and Sarkar A., 2003, Low Reynolds number flow through sudden expansion - from a diffuser viewpoint, $J$. Energy Heat and Mass Transfer, Vol. 25, pp. 46-66.

Chakrabarti S., Ray S. and Sarkar A.,2008, Numerical analysis for sudden expansion with fence in low Reynolds number regime, J. Energy Heat and Mass Transfer, Vol. 30, pp. 131-148.

Chakrabarti, S, Rao, S. and Mandal, D. K. 2010, Numerical Simulation of the Performance of a Sudden Expansion with Fence as a Diffuser in Low Reynolds Number Regime, ASME Journal of Engineering for Gas Turbines and Power, Vol. 132, No.11, 114502-1-4.

Cherdron, W., Durst, F. and Whitelaw, J. H., 1978, Asymmetric flows and instabilities in symmetric ducts with a sudden expansion, J. Fluid Mech., Vol. 84, pp. 13-31.

Choi, H., Hinze, M. and Kunisch, K., 1999, Instantaneous control of backward-facing step flows, Appl. Numer. Maths, Vol. 31, pp $133-158$.

Dejoan, A. and Leschziner, M. A., 2004, Large eddy simulation of periodically perturbed separated flow over a backward-facing step, Intl J. Heat Fluid flow, Vol. 25, pp. 581-592.

Denham, M. K. and Patrick, M. A., 1974, Laminar flow over a downstream-facing step in a twodimensional flow channel, Trans. Inst. Chem. Engrs, Vol. 52, pp. 361-367.

Durst, F., Melling, A. and Whitelaw, J. H., 1974, Low Reynolds number flow over a plane Symmetrical sudden expansion, $J$. Fluid Mech., Vol. 64, pp. 111-128. 
Durst, F. , Pereira, J. C. F. and Tropea, C.,1993, The plane symmetric sudden-expansion flow at low Reynolds numbers, J . Fluid Mech., Vol. 248, pp. 567-581.

Fearn, R. M., Mullin, T. and Cliffe, K. A., 1990, Nonlinear flow phenomena in a symmetric sudden expansion, J. Fluid Mech., Vol. 211, pp. 595-608.

Fortin, A., Jardak, M., Gervais, J. J. and Pierre, R., 1997, Localization of Hopf bifurcations in fluid flow problems, Intl J. Numer. Meth. Fluids, Vol. 24, pp. 1185-1210.

Gartling, D. K., 1990, A test problem for outflow boundary-conditions flow over a backward-facing step, Intl J. Numer. Meth. Fluids, Vol. 11, pp. 953-967.

Ghia, K. N., Osswald, G. A. and Ghia, U., 1989, Analysis of incompressible massively separated viscous flows using unsteady Navier-Stokes equations, Intl J. Numer. Meth. Fluids, Vol. 9, pp. 1025-1050.

Ghosh, S., Pratihar, D. K., Maiti, B. and Das, P. K., 2009, An evolutionary optimization of diffuser shapes based on CFD simulations, International Journal for Numerical Methods in Fluids, 2009, Published online.

Gresho, P. M., Gartling, D. K., Torczynski, J. R., Cliffe, K. A., Winters, K. H., Garratt, T. J., Spence, A. and Goodrich, J. W., 1993, Is the steady viscous incompressible two-dimensional flow over a backward-facing step at Re $=800$ stable? Intl J. Numer. Meth. Fluids, Vol. 17, pp. 501-541.

Guerrero, J. S. P. and Cotta, R. M., 1996, Benchmark integral transform results for flow over a backward-facing step, Comput. Fluids, Vol. 25, pp. 527-540.

Hawa, T. and Rusak, Z.,2001, The dynamics of a laminar flow in a symmetric channel with a sudden expansion, J. Fluid Mech., Vol. 436, pp. 283-320.

Heskestad, G., 1965, An edge suction effect, AIAA journal, Vol. 3, pp. 1958-61.

Heskestad, G., 1968, A suction scheme applied to flow through sudden enlargement, j. basic engg., Trans. ASME series D, Vol. 90, Pp. 541-52.

Howard, J. H. G., Thornton-Trump, A. B., and Henseler, H. J., 1967, Performance and Flow Regimes for Annular Diffusers, ASME Paper No. 67-WA/FE- 21.

Johnston, L H., 1953, The Effect of Inlet Conditions on the Flow in Annular Diffusers, British Aeronautical Research Council, C. P. No. 178.

Kaiktsis, L., Karniadakis, G. E. and Orszag, S. A., 1991, Onset of three-dimensionality, equilibria, and early transition in flow over a backward-facing step, J. Fluid Mech., Vol. 231, pp. 501-528.

Kaiktsis, L., Karniadakis, G. E. and Orszag, S. A., 1996, Unsteadiness and convective instabilities in two-dimensional flow over a backward-facing step, J. Fluid Mech., Vol. 321, pp. 157-187.

Kibicho, K. and Sayers, A. T., 2008, Benchmark Experimental Data for Fully Stalled Wide-Angled Diffusers, Journal of Fluids Engineering, Vol. 130, 104502-1-4.

Kobayashi, T., Morinishi, Y. and Oh, Keon-Je., 1992, Large eddy simulation of backward-facing step flow, Communications in Applied Numerical Methods, Vol. 8, No. 7, pp. 431-441.

Kosma, Z., 2000, Computing laminar incompressible flows over a backward-facing step using Newton iterations, Mech. Res. Commun., Vol. 27, pp. 235-240.

Koutmos, P. and Mavridis, C., 1997, A computational investigation of unsteady separated flow, Intl J. Heat Fluid Flow, Vol. 18, pp. 297-306.

Lan, H., Armaly, B. F., Drallmeier, J. A., 2009, Turbulent Forced Convection in a Plane Asymmetric Diffuser: Effect of Diffuser Angle, Journal of Heat Transfer, Vol. 131, pp. 071702-1-8.

Lee, T., Huteau, F. and Mateescu, D. 2000, Flow past a 2-D backward-facing step with an oscillating wall, J. Fluids Struct., Vol. 14, pp. 691-696.

Manica, R. and Bortoli, A. L. De, 2004, Simulation of sudden expansion flows for power-law fluids, J. Non-Newtonian Fluid Mech., Vol. 121, pp. 35-40.

Mohanarangama, K., Tua, J.Y. and Chenb, L., 2008, Numerical study of particle dispersion behind a sudden expansion geometry and its effect on step heights, Computers and Chemical Engineering, Vol. 32, pp. 3187-3197.

Meri, A. and Wengle, H., 2004, DNS and LES of Turbulent Backward-Facing Step Flow Using 2nd-and 4th-Order Discretization, Advances in LES of Complex Flows, Fluid Mechanics and Its Applications, Vol. 65, No. 2, pp. 99-114.

Neofytou, P., 2006, Transition to asymmetry of generalised Newtonian fluid flows through a symmetric sudden expansion, $J$. Non-Newtonian Fluid Mech., Vol. 133, pp. 132-140.

Nie, J. H. and Armaly, B. F., 2004, Reverse flow regions in three-dimensional backward-facing step flow, Intl J. Heat Mass Transfer, Vol. 47, pp. 4713-4720.

Patankar S.V.,1980, Numerical heat transfer and fluid flow, Hemisphere Publications.

Poole, R.J., Alves, M.A., Oliveira, P.J. and Pinho, F.T., 2007, Plane sudden expansion flows of viscoelastic liquids, J. NonNewtonian Fluid Mech., Vol. 146, pp. 79-91.

Raghunathan S. and Cooper R. K.,2000, Passive boundary layer control with slots in short diffusers, J. Fluids Engg., Vol. 122, pp. 177-179. 
Revueltaa, A, 2005, On the two-dimensional flow in a sudden expansion with large expansion ratios, physics of fluids, Vol. 17, pp. 1-4.

Rosa, S. and Pinho, F.T., 2006, Pressure drop coefficient of laminar Newtonian flow in axisymmetric diffusers, International Journal of Heat and Fluid Flow, Vol. 27, pp. 319-328.

Schafer, F., Breuer, M. and Durst, F.,2009, The dynamics of the transitional flow over a backward-facing step, J. Fluid Mech., Vol. 623, pp. 85-119.

Senthil Kumar, D., Murugesan, K. and Gupta A., 2010, Effect of thermo-solutal stratification on recirculation flow patterns in a backward-facing step channel flow, Int. J. Numer. Meth. Fluids, Vol. 64(2), pp. 163-186.

Sheu, T. W. H. and Rani, H. P., 2006, Exploration of vortex dynamics for transitional flows in a three-dimensional backwardfacing step channel, J. Fluid Mech., Vol. 550, pp. 61-83.

Sobey, I. J. and Drazin, P. G., 1986, Bifurcations of two-dimensional channel flows, J. Fluid Mech., Vol. 171, pp 263-287.

Thiruvengadam, M., Armaly, B. F. and Drallmeier, J. A., 2007, Three-Dimensional Mixed Convection in Plane SymmetricSudden Expansion: Bifurcated Flow Regime, Journal of Heat Transfer, Vol. 129, pp. 819-826.

Tornblom, O., Lindgren, B. and Johansson, A. V., 2009, The separating flow in a plane asymmetric diffuser with $8.5^{\circ}$ opening angle: mean flow and turbulence statistics, temporal behaviour and flow structures, J. Fluid Mech., Vol. 636, pp. 337-370.

Walker A. D., Denman P. A. and McGuirk J. J.,2004, Experimental and computational study of hybrid diffusers for gas turbine combustors, J. Engg. Gas Turbines and Power, Vol. 126, pp.717-725.

\section{Nomenclature}

$\begin{array}{ll}A & \text { Area at any section, }\left[\mathrm{m}^{2}\right] \\ A R & \text { Aspect ratio or Expansion ratio, exit area/inlet area } \\ d & \text { Distance (perpendicular to axis) between inlet duct surface and fence, }[\mathrm{m}] \\ d A & \text { Elemental area, }\left[\mathrm{m}^{2}\right] \\ F S A & \text { Fence subtended angle [in degrees] } \\ L_{i} & \text { Length of inlet duct, }[\mathrm{m}] \\ L_{e x} & \text { Length of the exit duct, }[\mathrm{m}] \\ L_{f} & \text { Distance of fence from throat, }[\mathrm{m}] \\ L_{p} & \text { Distance of maximum static pressure from throat, }[\mathrm{m}] \\ L_{r} & \text { Reattachment length, }[\mathrm{m}] \\ P \text { or } p & \text { Static pressure, }\left[\mathrm{N} / \mathrm{m}^{2}\right] \\ P_{a v g} & \text { Average static pressure, }\left[\mathrm{N} / \mathrm{m}^{2}\right] \\ \left.P_{s}\right] & \text { Stagnation pressure, }\left[\mathrm{N} / \mathrm{m}^{2}\right] \\ \left.p_{\text {sav }}\right] & \text { Average stagnation pressure, }\left[\mathrm{N} / \mathrm{m}^{2}\right] \\ R e & \text { Flow Reynolds number } \\ U, v & \text { Velocity components in } \mathrm{x} \text { and y directions in the Cartesian co-ordinate system, }[\mathrm{m} / \mathrm{s}] \\ U & \text { Average velocity, }[\mathrm{m} / \mathrm{s}] \\ \overline{\mathrm{V}} & \text { Velocity vector } \\ W_{l} & \text { Width of inlet duct, }[\mathrm{m}] \\ W_{2} & \text { Width of exit duct, }[\mathrm{m}] \\ X, y & \text { Cartesian co-ordinates, }[\mathrm{m}] \\ \eta_{\mathrm{d}} & \text { Diffuser effectiveness, }[\%] \\ \mu & \text { Dynamic viscosity, }[\mathrm{Kg} / \mathrm{m} . \mathrm{s}] \\ P & \text { Density of the fluid, }\left[\mathrm{Kg} / \mathrm{m}^{3}\right] \\ \text { Supercripts } & \\ * & \text { Dimensional terms } \\ 1 & \text { Inlet } \\ 2 & \text { Exit } \\ & \end{array}$

Biographical notes

Dr. D. K. Mandal completed his Masters Degree in Heat Power Engineering from Bengal Engineering and Science University, Shibpur, West Bengal in the year 1999. He did his Ph.D in the year of 2010 from the same University. He is currently an Associate Professor and Head of Mechanical Engineering Department, College of Engineering and Management, Kolaghat, West Bengal. His research fields are computational fluid dynamics and bio-fluid dynamics. He has published 13 international journals and 15 international conference proceedings. 
Mr. S. Bandyopadhyay completed his Masters Degree in Heat Power Engineering from BIT Mesra in the year 2008. He is currently an assistant professor of Mechanical Engineering Department, College of Engineering and Management, Kolaghat, West Bengal. His research field is computational fluid dynamics. He has published 1 international journal and 1 international conference proceeding.

Dr. Somnath Chakrabarti completed his B.E. in Mech. Engg. in the year 1978 from Bengal Engineering College, Shibpur, M.Tech in Thermal Engineering in the year 1980 from IIT Kharagpur. He did his Ph.D in the year of 2004 from Jadavpur University. He has worked 11 years in Damodar Valley Corporation from 1980 to 1991 in the field of operation, commissioning, and fuel \& efficiency of pulverized coal fired thermal power units. Now he is working as an Associate Professor in Mechanical Engg. Deptt. in Bengal Engineering College. He has published 20 papers in peer reviewed International journals and 19 papers in International/National conference proceedings. He has authored the text book "Fundamentals of Renewable Energy Systems", under New Age International Publishers, New Delhi, in 2004. His area of research includes Fluid flow analysis; Energy analysis; Exergy analysis; Solar thermal systems; Integrated and hybrid energy systems.

Received November 2011

Accepted May 2012

Final acceptance in revised form June 2012 